\title{
Scour Characteristics and Equilibrium Scour Depth Prediction around Umbrella Suction Anchor Foundation under Random Waves
}

\author{
Ruigeng $\mathrm{Hu}^{1}$, Hongjun Liu ${ }^{2}$, Hao Leng ${ }^{1}$, Peng $\mathrm{Yu}^{3}$ and Xiuhai Wang ${ }^{1,2, *}$ \\ 1 College of Environmental Science and Engineering, Ocean University of China, Qingdao 266000, China; \\ huruigeng@stu.ouc.edu.cn (R.H.); 1h4517@stu.ouc.edu.cn (H.L.) \\ 2 Key Lab of Marine Environment and Ecology (Ocean University of China), Ministry of Education, \\ Qingdao 266000, China; hongjun@ouc.edu.cn \\ 3 Qingdao Geo-Engineering Survering Institute, Qingdao 266100, China; yp6650@stu.ouc.edu.cn \\ * Correspondence: showseas@ouc.edu.cn
}

Citation: Hu, R.; Liu, H.; Leng, H.; Yu, P.; Wang, X. Scour Characteristics and Equilibrium Scour Depth

Prediction around Umbrella Suction Anchor Foundation under Random Waves. J. Mar. Sci. Eng. 2021, 9, 886 https://doi.org/10.3390/jmse9080886

Received: 6 July 2021

Accepted: 13 August 2021

Published: 17 August 2021

Publisher's Note: MDPI stays neutra with regard to jurisdictional claims in published maps and institutional affiliations.

Copyright: (C) 2021 by the authors Licensee MDPI, Basel, Switzerland. This article is an open access article distributed under the terms and conditions of the Creative Commons Attribution (CC BY) license (https:// creativecommons.org/licenses/by/ $4.0 /)$

\begin{abstract}
A series of numerical simulation were conducted to study the local scour around umbrella suction anchor foundation (USAF) under random waves. In this study, the validation was carried out firstly to verify the accuracy of the present model. Furthermore, the scour evolution and scour mechanism were analyzed respectively. In addition, two revised models were proposed to predict the equilibrium scour depth $S_{\text {eq }}$ around USAF. At last, a parametric study was carried out to study the effects of the Froude number $F_{\mathrm{r}}$ and Euler number $E_{\mathrm{u}}$ for the $S_{\text {eq. }}$. The results indicate that the present numerical model is accurate and reasonable for depicting the scour morphology under random waves. The revised Raaijmakers's model shows good agreement with the simulating results of the present study when $K C_{\mathrm{s}, \mathrm{p}}<8$. The predicting results of the revised stochastic model are the most favorable for $n=10$ when $K C_{\mathrm{rms}, \mathrm{a}}<4$. The higher $F_{\mathrm{r}}$ and $E_{\mathrm{u}}$ both lead to the more intensive horseshoe vortex and larger $S_{\mathrm{eq}}$.
\end{abstract}

Keywords: scour; numerical investigation; random waves; equilibrium scour depth; $K C$ number

\section{Introduction}

The rapid expansion of cities tends to cause social and economic problems, such as environmental pollution and traffic jam. As a kind of clean energy, offshore wind power has developed rapidly in recent years. The foundation of offshore wind turbine (OWT) supports the upper tower, and suffers the cyclic loading induced by waves, tides and winds, which exerts a vital influence on the OWT system. The types of OWT foundation include the fixed and floating foundation, and the fixed foundation was used usually for nearshore wind turbine. After the construction of fixed foundation, the hydrodynamic field changes in the vicinity of the foundation, leading to the horseshoe vortex formation and streamline compression at the upside and sides of foundation respectively [1-4]. As a result, the neighboring soil would be carried away by the shear stress induced by vortex, and the scour hole would emerge in the vicinity of foundation. The scour holes increase the cantilever length, and weaken the lateral bearing capacity of foundation [5-9]. Moreover, the natural frequency of OWT system increases with the increase of cantilever length, causing the resonance occurs when the system natural frequency equals the wave or wind frequency [10-12]. Given that, an innovative foundation called umbrella suction anchor foundation (USAF) has been designed for nearshore wind power. The previous studies indicated the USAF was characterized by the favorable lateral bearing capacity with the low cost $[6,13,14]$. The close-up of USAF is shown in Figure 1, and it includes six parts: 1-interal buckets, 2-external skirt, 3-anchor ring, 4-anchor branch, 5-supporting rod, 6telescopic hook. The detailed description and application method of USAF can be found in reference [13]. 


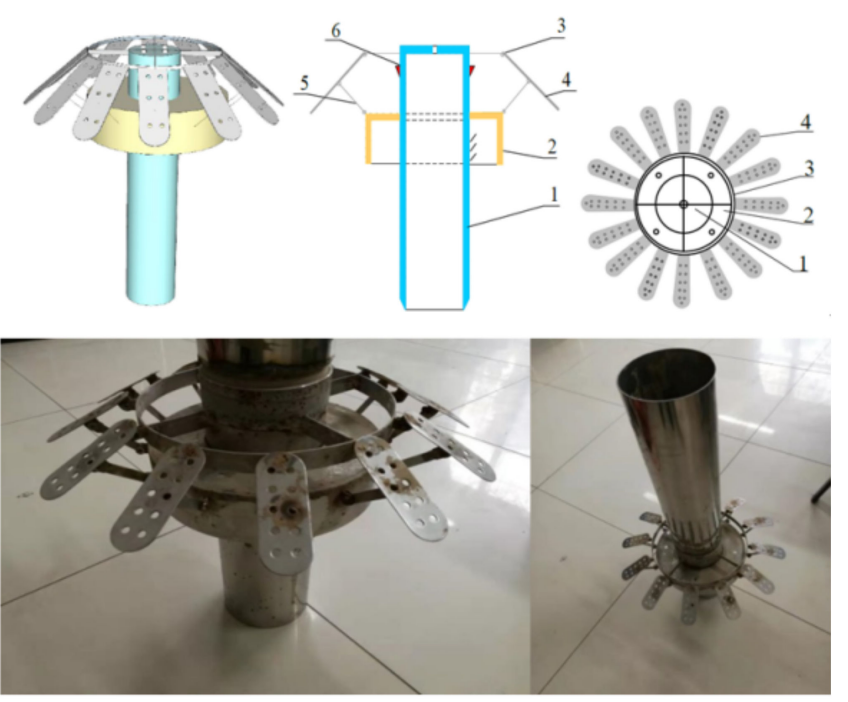

Figure 1. The close-up of umbrella suction anchor foundation (USAF).

Numerical and experimental investigations of scour around OWT foundation under steady currents and waves have been extensively studied by many researchers [1,2,15-24]. The seabed scour can be classified as two types according to Shields parameter $\theta$, i.e., clear bed scour $\left(\theta<\theta_{\mathrm{cr}}\right)$ or live bed scour $\left(\theta>\theta_{\mathrm{cr}}\right)$. Due to the set of foundation, the adverse hydraulic pressure gradient exists at upstream foundation edges, resulting in the streamline separation between boundary layer flow and seabed. The separating boundary layer ascended at upstream anchor edges and developed into the horseshoe vortex. Then, the horseshoe vortex moved downstream gradually along the periphery of the anchor, and the vortex shed off continually at the lee-side of the anchor, i.e., wake vortex. The core of wake vortex is a negative pressure center, liking a vacuum cleaner. Hence, the soil particles were swirled into the negative pressure core and carried away by wake vortexes. At the same time, the onset of scour at rear side occurred. Finally, the wake vortex became downflow when the turbulence energy could not support the survival of wake vortex. According to Tavouktsoglou et al. [25], the scale of pile wall boundary layer is proportional to $1 / \ln \left(R_{\mathrm{d}}\right)\left(R_{\mathrm{d}}\right.$ is pile Reynolds), which means the turbulence intensity induced by the flow-structure interaction would decrease with $R_{\mathrm{d}}$ increases, but the effects of $R_{\mathrm{d}}$ can be neglected only if the flow around the foundation is fully turbulent [26]. According to previous studies [1,15,27-32], the scour development around pile foundation under waves was significantly influenced by Shields parameter $\theta$ and $K C$ number simultaneously (calculated by Equation (1)). Sand ripples widely existed around pile under waves in the case of live bed scour, and the scour morphology is related with $\theta$ and $K C$. Compared with $\theta, K C$ has a greater influence on the scour morphology $[21,27,28]$. The influence mechanism of $K C$ on the scour around the pile is reflected in two aspects: the horseshoe vortex at upstream and wake vortex shedding at downstream.

$$
K C=\frac{U_{\mathrm{wm}} T}{D}
$$

where, $U_{\mathrm{wm}}$ is the maximum velocity of the undisturbed wave-induced oscillatory flow at the sea bottom above the wave boundary layer, $T$ is wave period, and $D$ is pile diameter.

There are two prerequisites to satisfy the formation of horseshoe vortex at upstream pile edges: (1) the incoming flow boundary layer with sufficient thickness and (2) the magnitude of upstream adverse pressure gradient making the boundary layer separating $[1,15,16,18,20]$. The smaller $K C$ results the lower adverse pressure gradient, and the boundary layer cannot separate, herein, there is almost no horseshoe vortex emerging at upside of pile. Sumer et al. [1,15] carried out several sets of wave flume experiments under regular and irregular waves respectively, and the experiment results show that there is no horseshoe 
vortex when $K C$ is less than 6 . While the scale and lifespan of horseshoe vortex increase evidently with the increase of $K C$ when $K C$ is larger than 6. Moreover, the wake vortex contributes to the scour at lee-side of pile. Similar with the case of horseshoe vortex, there is no wake vortex when $K C$ is less than 6 . The wake vortex is mainly responsible for scour around pile when $K C$ is greater than 6 and less than $O(100)$, while horseshoe vortex controls scour nearly when $K C$ is greater than $O(100)$.

Sumer et al. [1] found that the equilibrium scour depth was nil around pile when $K C$ was less than 6 under regular waves for live bed scour, while the equilibrium scour depth increased with the increase of $K C$. Based on that, Sumer proposed an equilibrium scour depth predicting equation (Equation (2)). Carreiras et al. [33] revised Sumer's equation with $m=0.06$ for nonlinear waves. Different with the findings of Sumer et al. [1] and Carreiras et al. [33], Corvaro et al. [21] found the scour still occurred for $K C \approx 4$, and proposed the revised equilibrium scour depth predicting equation (Equation (3)) for $K C>4$.

Rudolph and Bos [2] conducted a series of wave flume experiments to investigate the scour depth around monopile under waves only, waves and currents combined respectively, indicting $K C$ was one of key parameters in influencing equilibrium scour depth, and proposed the equilibrium scour depth predicting equation (Equation (4)) for low $K C(1<K C<10)$. Through analyzing the extensive data from published literatures, Raaijmakers and Rudolph [34] developed the equilibrium scour depth predicting equation (Equation (5)) for low KC, which was suitable for waves only, waves and currents combined. Khalfin [35] carried out several sets of wave flume experiments to study scour development around monopile, and proposed the equilibrium scour depth predicting equation (Equation (6)) for low $K C(0.1<K C<3.5)$. Different with above equations, the Khalfin's equation considers the Shields parameter $\theta$ and $K C$ number simultaneously in predicting equilibrium scour depth. The flow reversal occurred under through in one wave period, so sand particles would be carried away from lee-side of pile to upside, resulting in sand particles backfilled into the upstream scour hole [20,29]. Considering the backfilling effects, Zanke et al. [36] proposed the equilibrium scour depth predicting equation (Equation (7)) around pile by theoretical analysis, and the equation is suitable for the whole range of $K C$ number under regular waves and currents combined.

$$
S / D=1.3(1-\exp ([-m(K C-6)])
$$

where, $m=0.03$ for linear waves.

$$
\begin{gathered}
S / D=1.3(1-\exp ([-0.02(K C-4)]) \\
S / D=1.3 \gamma K_{\text {wave }} K_{h_{\mathrm{w}}}
\end{gathered}
$$

where, $\gamma$ is safety factor, depending on design process, typically $\gamma=1.5, K_{\text {wave }}$ is correction factor considering wave action, $K_{h \mathrm{w}}$ is correction factor considering water depth.

$$
S / D=1.5\left[\tanh \left(\frac{h_{\mathrm{w}}}{D}\right)\right] K_{\text {wave }} K_{h_{\mathrm{w}}}
$$

where, $h_{\mathrm{w}}$ is water depth.

$$
S / D=0.0753\left(\sqrt{\frac{\theta}{\theta_{\mathrm{cr}}}}-0.5\right) \quad K C^{0.68}
$$

where, $\theta$ is shields parameter, $\theta_{\mathrm{cr}}$ is critical shields parameter.

$$
\left.\begin{array}{l}
S / D=2.5\left(1-0.5 u / u_{c}\right) x_{r e l} \\
x_{r e l}=x_{e f f} /\left(1+x_{e f f}\right) \\
x_{e f f}=0.03\left(1-0.35 u_{\mathrm{cr}} / u\right)(K C-6)
\end{array}\right\}
$$


where, $u$ is near-bed orbital velocity amplitude, $u_{c}$ is critical velocity corresponding the onset of sediment motion.

$$
S / D=1.3\left\{1-\exp \left[-0.03\left(K C^{2} \ln n+36\right)^{1 / 2}-6\right]\right\}
$$

where, $n$ is the $1 / n^{\prime}$ th highest wave for random waves

For predicting equilibrium scour depth under irregular waves, i.e., random waves, Sumer and Fredsøe [16] found it's suitable to take Equation (2) to predict equilibrium scour depth around pile under random waves with the root-mean-square (RMS) value of nearbed orbital velocity amplitude $U_{\mathrm{m}}$ and peak wave period $T_{\mathrm{P}}$ to calculate $K C$. Khalfin [35] recommended the RMS wave height $H_{\mathrm{rms}}$ and peak wave period $T_{\mathrm{P}}$ were used to calculate KC for Equation (6). References [37-40] developed a series of stochastic theoretical models to predict equilibrium scour depth around pile under random waves, nonlinear random waves plus currents respectively. The stochastic approach thought the $1 / \mathrm{n}^{\prime}$ th highest wave were responsible for scour in vicinity of pile under random waves, and the $K C$ was calculated in Equation (8) with $U_{\mathrm{m}}$ and mean zero-crossing wave period $T_{\mathrm{z}}$. The results calculated by Equation (8) agree well with experimental values of Sumer and Fredsøe [16] if the $1 / 10^{\prime}$ th highest wave was used. To author's knowledge, the stochastic approach proposed by Myrhaug and Rue [37] is the only theoretical model to predict equilibrium scour depth around pile under random waves for the whole range of $K C$ number in published documents. Other methods of predicting scour depth under random waves are mainly originated from the equation for regular waves-only, waves and currents combined, which are limited to the large $K C$ number, such as $K C>6$ for Equation (2) and $K C>4$ for Equation (3) respectively. However, situations with relatively low $K C$ number $(K C<4)$ often occur in reality, for example, monopile or suction anchor for OWT foundations in ocean environment. Moreover, local scour around OWT foundations under random waves has not yet been investigated fully. Therefore, further study are still needed in the aspect of scour around OWT foundations with low KC number under random waves. Given that, this study presents the scour sediment model around umbrella suction anchor foundation (USAF) under random waves. In this study, a comparison of equilibrium scour depth around USAF between this present numerical models and the previous theoretical models and experimental results was presented firstly. Then, this study gave a comprehensive analysis for the scour mechanisms around USAF. After that, two revised models were proposed according to the model of Raaijmakers and Rudolph [34] and the stochastic model developed by Myrhaug and Rue [37] respectively to predict the equilibrium scour depth. Finally, a parametric study was conducted to study the effects of the Froude number $\left(F_{\mathrm{r}}\right)$ and Euler number $\left(E_{\mathrm{u}}\right)$ to equilibrium scour depth respectively.

\section{Numerical Method}

\subsection{Governing Equations of Flow}

The following equations adopted in present model are already available in Flow $3 \mathrm{D}$ software. The authors used these theoretical equations to simulate scour in random waves without modification. The incompressible viscous fluid motion satisfies the Reynolds-averaged Navier-Stokes (RANS) equation, so the present numerical model solves RANS equations:

$$
\begin{gathered}
\frac{\partial u}{\partial t}+\frac{1}{V_{F}}\left(u A_{x} \frac{\partial u}{\partial x}+v A_{y} \frac{\partial u}{\partial y}+w A_{z} \frac{\partial u}{\partial z}\right)=-\frac{1}{\rho_{\mathrm{f}}} \frac{\partial p}{\partial x}+G_{x}+f_{x} \\
\frac{\partial v}{\partial t}+\frac{1}{V_{F}}\left(u A_{x} \frac{\partial v}{\partial x}+v A_{y} \frac{\partial v}{\partial y}+w A_{z} \frac{\partial v}{\partial z}\right)=-\frac{1}{\rho_{\mathrm{f}}} \frac{\partial p}{\partial y}+G_{y}+f_{y} \\
\frac{\partial w}{\partial t}+\frac{1}{V_{F}}\left(u A_{x} \frac{\partial w}{\partial x}+v A_{y} \frac{\partial w}{\partial y}+w A_{z} \frac{\partial w}{\partial z}\right)=-\frac{1}{\rho_{\mathrm{f}}} \frac{\partial p}{\partial z}+G_{z}+f_{z}
\end{gathered}
$$


where, $V_{F}$ is the volume fraction; $u, v$, and $w$ are the velocity components in $x, y, z$ direction respectively with Cartesian coordinates; $A_{i}$ is the area fraction; $\rho_{\mathrm{f}}$ is the fluid density, $f_{i}$ is the viscous fluid acceleration, $G_{i}$ is the fluid body acceleration $(i=x, y, z)$.

\subsection{Turbulent Model}

The turbulence closure is available by the turbulent model, such as one-equation, the one-equation $k-\varepsilon$ model, the standard $k-\varepsilon$ model, $R N G k-\varepsilon$ turbulent model and large eddy simulation (LES) model. The LES model requires very fine mesh grid, so the computational time is large, which hinders the LES model application in engineering. The RNG $k-\varepsilon$ model can reduce computational time greatly with high accuracy in the near-wall region. Furthermore, the $R N G k-\varepsilon$ model computes the maximum turbulent mixing length dynamically in simulating sediment scour model. Therefore, the $R N G k-\varepsilon$ model was adopted to study the scour around anchor under random waves [41,42].

$$
\begin{array}{r}
\frac{\partial k_{T}}{\partial T}+\frac{1}{V_{F}}\left(u A_{x} \frac{\partial k_{T}}{\partial x}+v A_{y} \frac{\partial k_{T}}{\partial y}+w A_{z} \frac{\partial k_{T}}{\partial z}\right)=P_{T}+G_{T}+\operatorname{Diff}_{k_{T}}-\varepsilon_{k_{T}} \\
\frac{\partial \varepsilon_{T}}{\partial T}+\frac{1}{V_{F}}\left(u A_{x} \frac{\partial \varepsilon_{T}}{\partial x}+v A_{y} \frac{\partial \varepsilon_{T}}{\partial y}+w A_{z} \frac{\partial \varepsilon_{T}}{\partial z}\right)=\frac{C D I S 1 \varepsilon_{T}}{k_{T}}\left(P_{T}+C D I S 3 G_{T}\right)+\operatorname{Diff} f_{\varepsilon}-\frac{C D I S 2 \varepsilon_{T}^{2}}{k_{T}}
\end{array}
$$

where, $k_{T}$ is specific kinetic energy involved with turbulent velocity, $G_{T}$ is the turbulent energy generated by buoyancy; $\varepsilon_{T}$ is the turbulent energy dissipating rate, $P_{T}$ is the turbulent energy, Diff $f_{\varepsilon}$ and Diff $f_{T}$ are diffusion terms associated with $V_{F}, A_{i} ; C D I S 1, C D I S 2$ and CDIS3 are dimensionless parameters, and CDIS1, CDIS3 have default values of 1.42, 0.2 respectively. CDIS2 can be obtained from $P_{T}$ and $k_{T}$.

\subsection{Sediment Scour Model}

The sand particles may suffer four processes under waves, i.e., entrainment, bed load transport, suspended load transport, and deposition, so the sediment scour model should depict the above processes efficiently. In present numerical simulation, the sediment scour model includes the following aspects:

\subsubsection{Entrainment and Deposition}

The combination of entrainment and deposition determines the net scour rate of seabed in present sediment scour model. The entrainment lift velocity of sand particles was calculated as [43]:

$$
\mathbf{u}_{\text {lift }, \mathrm{i}}=\alpha_{i} n_{\boldsymbol{s}} d_{*}^{0.3}\left(\theta-\theta_{\mathrm{cr}}\right)^{1.5} \sqrt{\frac{\|g\| d_{i}\left(\rho_{i}-\rho_{\mathrm{f}}\right)}{\rho_{\mathrm{f}}}}
$$

where, $\alpha_{i}$ is the entrainment parameter, $\boldsymbol{n}_{\boldsymbol{s}}$ is the outward point perpendicular to the seabed, $d *$ is the dimensionless diameter of sand particles, which was calculated by Equation (15), $\theta_{\mathrm{cr}}$ is the critical Shields parameter, $g$ is the gravity acceleration, $d_{i}$ is the diameter of sand particles, $\rho_{i}$ is the density of seabed species.

$$
d_{*}=d_{i}\left(\frac{\|g\| \rho_{\mathrm{f}}\left(\rho_{i}-\rho_{\mathrm{f}}\right)}{\mu_{\mathrm{f}}^{2}}\right)^{1 / 3}
$$

where $\mu_{f}$ is the fluid dynamic viscosity.

In Equation (14), the entrainment parameter $\alpha_{i}$ confirms the rate at which sediment erodes when the given shear stress is larger than the critical shear stress, and the recommended value 0.018 was adopted according to the experimental data of Mastbergen and Von den Berg [43]. $\boldsymbol{n}_{\mathbf{s}}$ is the outward pointing normal to the seabed interface, and $\boldsymbol{n}_{\mathbf{s}}=(0,0,1)$ according to the Cartesian coordinates used in present numerical model. 
The shields parameter was obtained from the following equation:

$$
\theta=\frac{U_{\mathrm{f}, \mathrm{m}}^{2}}{\left(\rho_{i} / \rho_{\mathrm{f}}-1\right) g d_{50}}
$$

where, $U_{\mathrm{f}, \mathrm{m}}$ is the maximum value of the near-bed friction velocity; $d_{50}$ is the median diameter of sand particles. The detailed calculation procedure of $\theta$ was available in Soulsby [44].

The critical shields parameter $\theta_{\text {cr }}$ was obtained from the Equation (17) [44]

$$
\theta_{\mathrm{cr}}=\frac{0.3}{1+1.2 d_{*}}+0.055\left[1-\exp \left(-0.02 d_{*}\right)\right]
$$

The sand particles begin to deposit on seabed when the turbulence energy weaken and cann't support the particles suspending. The setting velocity of the particles was calculated from the following equation [44]:

$$
\mathbf{u}_{\text {settling }, i}=\frac{v_{\mathrm{f}}}{d_{i}}\left[\left(10.36^{2}+1.049 d_{*}^{3}\right)^{0.5}-10.36\right]
$$

where $v_{\mathrm{f}}$ is the fluid kinematic viscosity.

\subsubsection{Bed Load Transport}

This is called bed load transport when the sand particles roll or bounce over the seabed and always have contact with seabed. The bed load transport velocity was computed by [45]:

$$
\mathbf{u}_{\text {bedload }, i}=\frac{q_{\mathrm{b}, i}}{\delta_{i} c_{\mathrm{b}, i} i_{\mathrm{b}}}
$$

where, $q_{\mathrm{b}, i}$ is the bed load transport rate, which was obtained from Equation (20), $\delta_{i}$ is the bed load thickness, which was calculated by Equation (21), $c_{\mathrm{b}, i}$ is the volume fraction of sand $i$ in the multiple species, $f_{\mathrm{b}}$ is the critical packing fraction of the seabed.

$$
\begin{aligned}
q_{\mathrm{b}, i} & =8\left[\|g\|\left(\frac{\rho_{i}-\rho_{\mathrm{f}}}{\rho_{\mathrm{f}}}\right) d_{i}^{3}\right]^{1 / 2} \\
\delta_{i} & =0.3 d_{*}^{0.7}\left(\frac{\theta}{\theta_{\mathrm{cr}}}-1\right)^{0.5} d_{i}
\end{aligned}
$$

\subsubsection{Suspended Load Transport}

Through the following transport equation, the suspended sediment concentration could be acquired.

$$
\frac{\partial C_{\mathrm{s}, i}}{\partial t}+\nabla\left(\mathbf{u}_{\mathrm{s}, i} C_{\mathrm{s}, i}\right)=\nabla \nabla\left(D_{\mathrm{f}} C_{\mathrm{s}, i}\right)
$$

where, $C_{\mathrm{s}, i}$ is the suspended sand particles mass concentration of sand $i$ in the multiple species, $\mathbf{u}_{\mathrm{s}, i}$ is the sand particles velocity of sand $i, D_{\mathrm{f}}$ is the diffusivity.

The velocity of sand $i$ in the multiple species could be obtained from the following equation:

$$
\mathbf{u}_{\mathrm{s}, i}=\overline{\mathbf{u}}+\mathbf{u}_{\mathrm{settling}, i} c_{\mathrm{s}, i}
$$

where, $\overline{\mathbf{u}}$ is the velocity of mixed fluid-particles, which can be calculated by the RANS equation with turbulence model, $c_{\mathrm{s}, i}$ is the suspended sand particles volume concentration, which was computed from Equation (24).

$$
c_{\mathrm{s}, i}=\frac{C_{\mathrm{s}, i}}{\rho_{i}}
$$




\section{Model Setup}

The seabed-USAF-wave three-dimensional scour numerical model was built using Flow-3D software. As shown in Figure 2, the model includes sandy seabed, USAF model, sea water, two baffles and porous media. The dimensions of USAF are shown in Table 1. The sandy bed ( $210 \mathrm{~m}$ in length, $30 \mathrm{~m}$ in width and $11 \mathrm{~m}$ in height) is made up of uniform fine sand with median diameter $d_{50}=0.041 \mathrm{~cm}$. The USAF model includes upper steel tube with the length of $20 \mathrm{~m}$, which was installed in the middle of seabed. The location of USAF is positioned at $140 \mathrm{~m}$ from the upstream inflow boundary and $70 \mathrm{~m}$ from the downstream outflow boundary. Two baffles were installed at two ends of seabed. In order to eliminate the wave reflection basically, the porous media was set at the outflow side on the seabed.

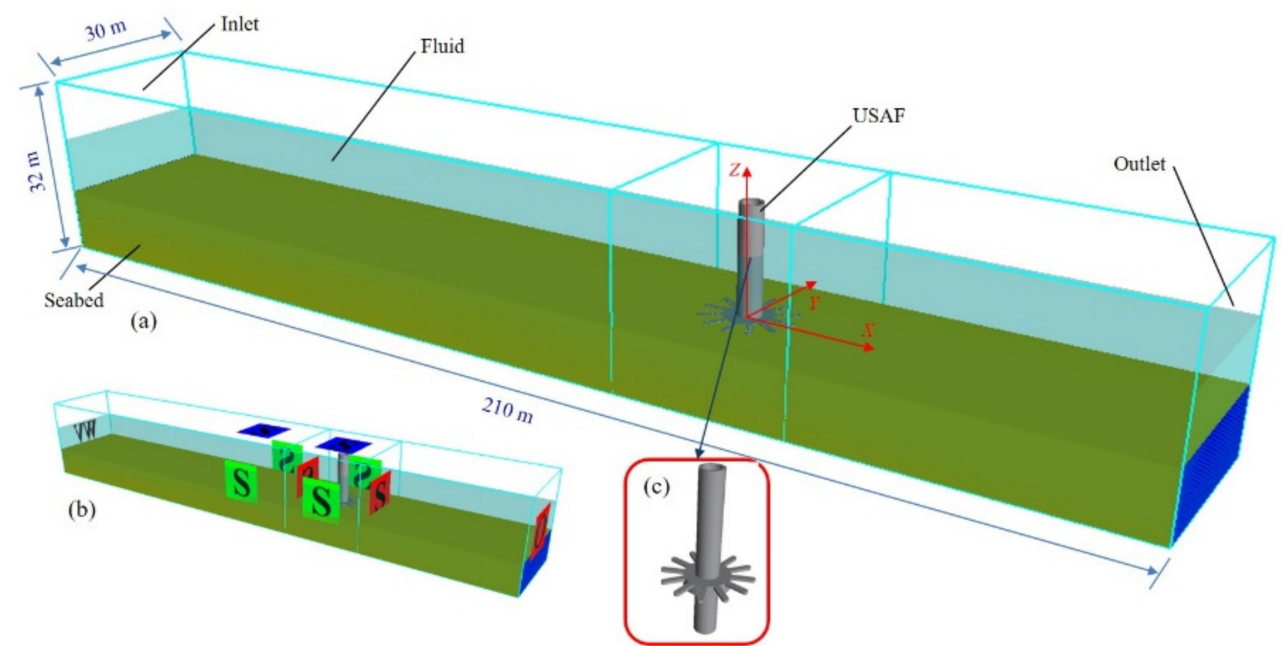

Figure 2. (a) The sketch of seabed-USAF-wave three-dimensional model; (b) boundary condation:Wvwave boundary, S-symmetric boundary, O-outflow boundary; (c) USAF model.

Table 1. Numerical simulating cases.

\begin{tabular}{cc}
\hline Item & Dimension/m \\
\hline Main tube height & 11.2 \\
Main tube diameter & 4 \\
Main tube wall thickness & 0.02 \\
Tube skirt height & 2 \\
Tube skirt diameter & 8 \\
Tube skirt wall thickness & 0.02 \\
Anchor branch length & 4 \\
Anchor branch thickness & 0.048 \\
\hline
\end{tabular}

\subsection{Mesh Geometric Dimensions}

In the simulation of the scour under the random waves, the model includes the umbrella suction anchor foundation, seabed and fluid. As shown in Figure 3, the model mesh includes global mesh grid and nested mesh grid, and the total number of grids is $1,812,000$. The basic procedure for building mesh grid consists of two steps. Step 1: Divide the global mesh using regular hexahedron with size of $0.6 \times 0.6$. The global mesh area is cubic box, embracing the seabed and whole fluid volume, and the dimensions are $210 \mathrm{~m}$ in length, $30 \mathrm{~m}$ in width and $32 \mathrm{~m}$ in height. The details of determining the grid size can see the following mesh sensitivity section. Step 2: Set nested fine mesh grid in vicinity of the USAF with size of $0.3 \times 0.3$ so as to shorten the computation cost and improve the calculation accuracy. The encryption range is $-15 \mathrm{~m}$ to $15 \mathrm{~m}$ in $x$ direction, $-15 \mathrm{~m}$ to $15 \mathrm{~m}$ in $y$ direction and $0 \mathrm{~m}$ to $32 \mathrm{~m}$ in $z$ direction, respectively. In order to accurately capture the free-surface dynamics, such as the fluid-air interface, the volume of fluid (VOF) method was adopted for tracking the free water surface. One specific algorithm called FAVORTM 
(Fractional Area/Volume Obstacle Representation) was used to define the fractional face areas and fractional volumes of the cells which are open to fluid flow.

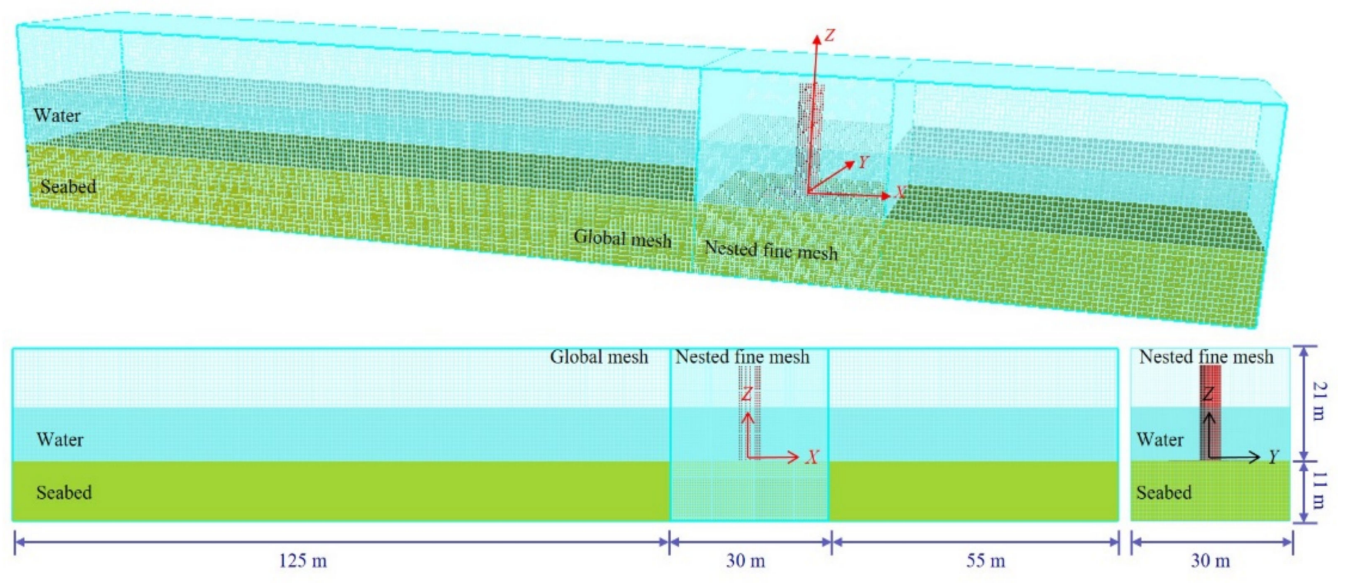

Figure 3. The sketch of mesh grid.

\subsection{Boundary Conditions}

As shown in Figure 2, the initial fluid length is $210 \mathrm{~m}$ as long as seabed. A wave boundary was specified at the upstream offshore end. The details of determining the random wave spectrum can see the following wave parameters section. The outflow boundary was set at the downstream onshore end. The symmetry boundary was used at the top and two sides of the model. The symmetric boundaries were the better strategy to improve the computation efficiency and save the calculation cost [46]. At the seabed bottom, the wall boundary was adopted, which means the $u=v=w=0$. Besides, the upper steel tube of USAF was set as no-slip condition.

\subsection{Wave Parameters}

The random waves with JONSWAP wave spectrum were used for all simulations as realistic representation of offshore conditions. The unidirectional JONSWAP frequency spectrum was described as [47]:

$$
S(\omega)=\frac{\alpha g^{2}}{\omega^{5}} \exp \left[-\frac{5}{4}\left(\frac{\omega_{\mathrm{p}}}{\omega}\right)^{4}\right] \gamma^{\exp \left[-\frac{\left(\omega-\omega_{\mathrm{p}}\right)^{2}}{2 \sigma^{2} \omega_{\mathrm{p}}^{2}}\right]}
$$

where, $\alpha$ is wave energy scale parameter, which is calculated by Equation (26), $\omega$ is frequency, $\omega_{\mathrm{p}}$ is wave spectrum peak frequency, which can be obtained from Equation (27). $\gamma$ is wave spectrum peak enhancement factor, in this study $\gamma=3.3 . \sigma$ is spectral width factor, $\sigma$ equals 0.07 for $\omega \leq \omega_{\mathrm{p}}$ and 0.09 for $\omega>\omega_{\mathrm{p}}$ respectively.

$$
\begin{gathered}
\alpha=0.0076\left(\frac{g X}{U^{2}}\right)^{-0.22} \\
\omega_{\mathrm{p}}=22\left(\frac{g}{U}\right)\left(\frac{g X}{U^{2}}\right)^{-0.33}
\end{gathered}
$$

where, $X$ is fetch length, $U$ is average wind velocity at $10 \mathrm{~m}$ height from mean sea level.

In present numerical model, the input key parameters include $X$ and $U$ for wave boundary with JONSWAP wave spectrum. The objective wave height and period are available by different combinations of $X$ and $U$. In this study, we designed 9 cases with different wave heights, periods and water depths for simulating scour around USAF under random waves (see Table 2). For random waves, the wave steepness $\varepsilon$ and Ursell number $U_{\mathrm{r}}$ were acquired form Equations (28) and (29) respectively 


$$
\begin{gathered}
\varepsilon=\frac{2 \pi}{g} \frac{H_{\mathrm{s}}}{T_{\mathrm{a}}^{2}} \\
U_{\mathrm{r}}=\frac{H_{\mathrm{s}}}{k^{2} h_{\mathrm{w}}^{3}}
\end{gathered}
$$

where, $H_{\mathrm{s}}$ is significant wave height, $T_{\mathrm{a}}$ is average wave period, $k$ is wave number, $h_{\mathrm{w}}$ is water depth. The Shield parameter $\theta$ satisfies $\theta>\theta_{\text {cr }}$ for all simulations in current study, indicating the live bed scour prevails.

Table 2. Numerical simulating cases.

\begin{tabular}{cccccc}
\hline Case & Water Depth/m & $\begin{array}{c}\text { Significant Wave Height } \\
\boldsymbol{H}_{\mathbf{1 / 3}} / \mathbf{m}\end{array}$ & Peak Period $\boldsymbol{T}_{\mathbf{p}} / \mathbf{s}$ & $\mathcal{\varepsilon}$ & $\boldsymbol{U}_{\mathbf{r}}$ \\
\hline 1 & 8 & 3.0 & 8.79 & 0.029 & 0.658 \\
2 & 8 & 3.5 & 9.53 & 0.029 & 0.928 \\
3 & 8 & 4.0 & 10.37 & 0.028 & 1.282 \\
4 & 8 & 4.5 & 10.76 & 0.029 & 1.567 \\
5 & 8 & 5.0 & 11.19 & 0.030 & 1.898 \\
6 & 9 & 5.0 & 11.19 & 0.030 & 1.480 \\
7 & 10 & 5.0 & 11.19 & 0.030 & 1.184 \\
8 & 11 & 5.0 & 11.19 & 0.030 & 0.965 \\
9 & 12 & 5.0 & 11.19 & 0.030 & 0.800 \\
\hline
\end{tabular}

\subsection{Mesh Sensitivity}

In this section, a mesh sensitivity analysis was conducted to investigate the influence of mesh grid size to results and make sure the calculation is mesh size independent and converged. Three mesh grid size were chosen: Mesh 1 -global mesh grid size of $0.75 \times 0.75$, nested fine mesh grid size of $0.4 \times 0.4$, and total number of grids 1,724,000, Mesh 2-global mesh grid size of $0.6 \times 0.6$, nested fine mesh grid size of $0.3 \times 0.3$, and total number of grids 1,812,000, Mesh 3-global mesh grid size of $0.4 \times 0.4$, nested fine mesh grid size of $0.2 \times 0.2$, and total number of grids $1,932,000$. The near-bed shear velocity $U_{*}$ is an important factor for influencing scour process $[1,15]$, so $U_{*}$ at the position of $(4,0,11.12)$ was evaluated under three mesh sizes. As the Figure 4 shown, the maximum error of shear velocity $\Delta U_{*_{1}, 2}$ is about $39.8 \%$ between the mesh 1 and mesh 2 , and $4.8 \%$ between the mesh 2 and mesh 3. According to the mesh sensitivity criterion adopted by Pang et al. [48], it's reasonable to think the results are mesh size independent and converged with mesh 2 . Additionally, the present model was built according to prototype size, and the mesh size used in present model is larger than the mesh size adopted by Higueira et al. [49] and Corvaro et al. [50]. If we choose the smallest cell size, it will take too much time. For example, the simulation with Mesh 3 required about $260 \mathrm{~h}$ by using a computer with Intel Xeon Scalable Gold 4214 CPU @24 Cores, 2.2 GHz and 64.00 GB RAM. Therefore, in this case, considering calculation accuracy and computation efficiency, the mesh 2 was chosen for all the simulation in this study.

The nested mesh block was adopted for seabed in vicinity of the USAF, which was overlapped with the global mesh block. When two mesh blocks overlap each other, the governing equations are by default solved on the mesh block with smaller average cell size (i.e., higher grid resolution). It is should be noted that the Flow 3D software used the moving mesh captures the scour evolution and automatically adjusts the time step size to be as large as possible without exceeding any of the stability limits, affecting accuracy, or unduly increasing the effort required to enforce the continuity condition [51]. 


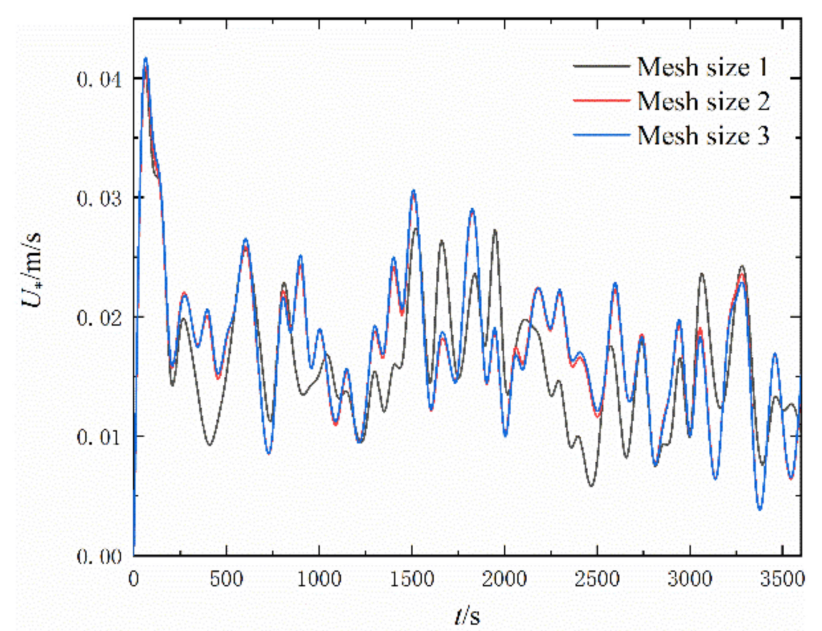

Figure 4. Comparison of near-bed shear velocity $U_{*}$ with different mesh grid size.

\subsection{Model Validation}

In order to verify the reliability of the present model, the results of present study were compared with the experimental data of Khosronejad et al. [52]. The experiment was conducted in an open channel with a slender vertical pile under unidirectional currents. The comparison of scour development between the present results and the experimental results is shown in Figure 5. The Figure 5 reveals that the present results agree well with the experimental data of Khosronejad et al. [52]. In the first stage, the scour depth increases rapidly. After that, the scour depth achieves a maximum value gradually. The equilibrium scour depth calculated by the present model is basically corresponding with the experimental results of Khosronejad et al. [52], although scour depth in the present model is slightly larger than the experimental results at initial stage.

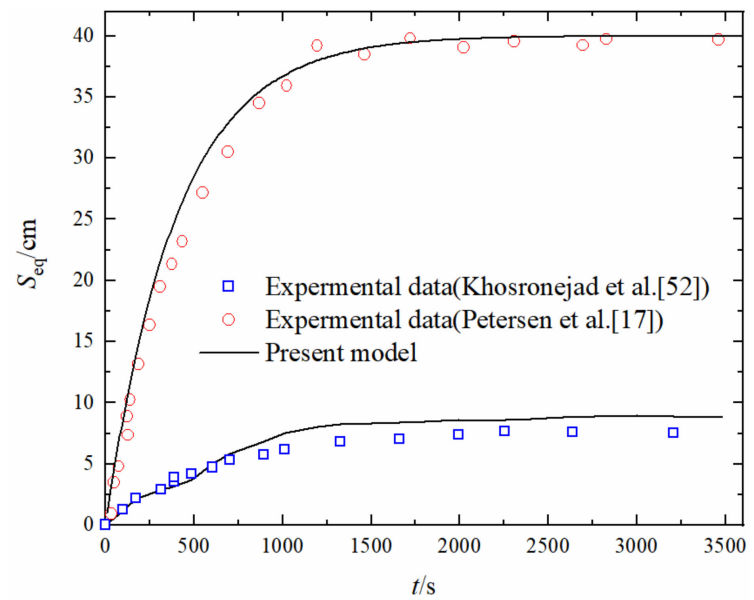

Figure 5. Comparison of time evolution of scour between the present study and Khosronejad et al. [52], Petersen et al. [17].

Secondly, another comparison was further conducted between the results of present study and the experimental data of Petersen et al. [17]. The experiment was carried out in a flume with a circular vertical pile in combined waves and current. Figure 4 shows a comparison of time evolution of scour depth between the simulating and the experimental results. As Figure 5 indicates, the scour depth in this study has good overall agreement with the experimental results proposed in Petersen et al. [17]. The equilibrium scour depth calculated by the present model is $0.399 \mathrm{~m}$, which equals to the experimental value basically. Overall, the above verifications prove the present model is accurate and capable in dealing with sediment scour under waves. 
In addition, in order to calibrate and validate the present model for hydrodynamic parameters, the comparison of water surface elevation was carried out with laboratory experiments conducted by Stahlmann [53] for wave gauge No. 3. The Figure 6 depicts the surface wave profiles between experiments and numerical model results. The comparison indicates that there is a good agreement between the model results and experimental values, especially the locations of wave crest and trough. Comparison of the surface elevation instructs the present model has an acceptable relative error, and the model is a calibrated in terms of the hydrodynamic parameters.

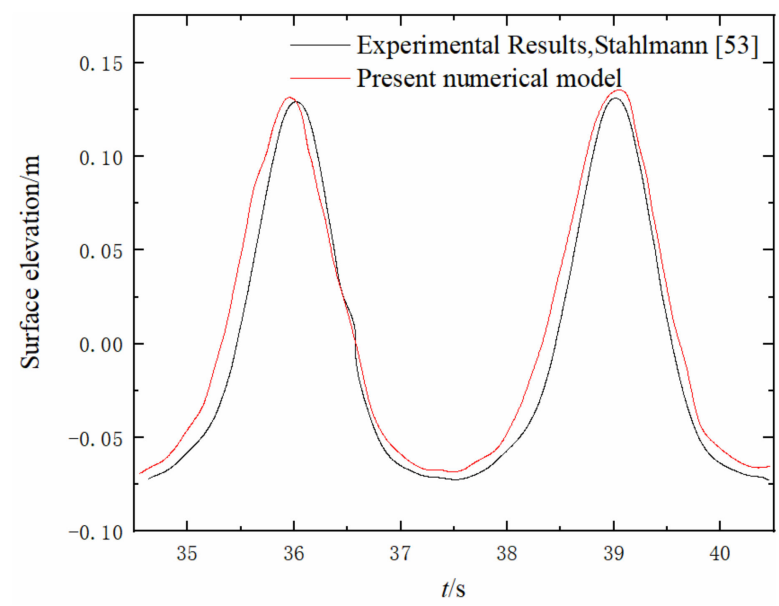

Figure 6. Comparison of surface elevation between the present study and Stahlmann [53].

Finally, another comparison was conducted for equilibrium scour depth or maximum scour depth under random waves with the experimental data of Sumer and Fredsøe [16] and Schendel et al. [22]. The Figure 7 shows the comparison between the numerical results and experimental data of Run01, Run05, Run21 and Run22 in Sumer and Fredsøe [16] and test A05 and A09 in Schendel et al. [22]. As shown in Figure 7, the equilibrium scour depth or maximum scour depth distributed within the \pm 30 error lines basically, meaning the reliability and accuracy of present model for predicting equilibrium scour depth around foundation in random waves. However, compared with the experimental values, the present model overestimated the equilibrium scour depth generally. Given that, a calibration for scour depth was carried out by multiplying the mean reduced coefficient 0.85 in following section.

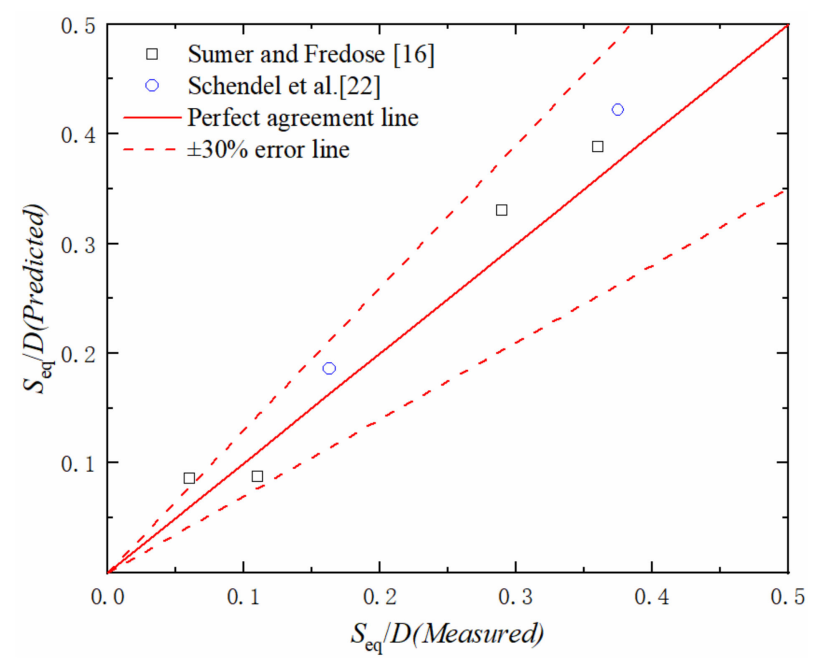

Figure 7. Comparison of equilibrium (or maximum) scour depth between the present study and Sumer and Fredsøe [16], Schendel et al. [22]. 
Through the various examination for hydrodynamic and morphology parameters, it can be concluded that the present model is a validated and calibrated model for scour under random waves. Thus, the present numerical model would be utilized for scour simulation around foundation under random waves.

\section{Numerical Results and Discussions}

\subsection{Scour Evolution}

Figure 8 displays the scour evolution for case 1-9. As shown in Figure 8a, the scour depth increased rapidly at the initial stage, and then slowed down at the transition stage, which attributes to the backfilling occurred in scour holes under live bed scour condition, resulting in the net scour decreasing. Finally, the scour reached the equilibrium state when the amount of sediment backfilling equaled to that of scouring in the scour holes, i.e., the net scour transport rate was nil. Sumer and Fredsøe [16] proposed the following formula for the scour development under waves

$$
S_{\mathrm{t}}=S_{\mathrm{eq}}\left(1-\exp \left(-t / T_{\mathrm{c}}\right)\right)
$$

where $T_{\mathrm{c}}$ is time scale of scour process.

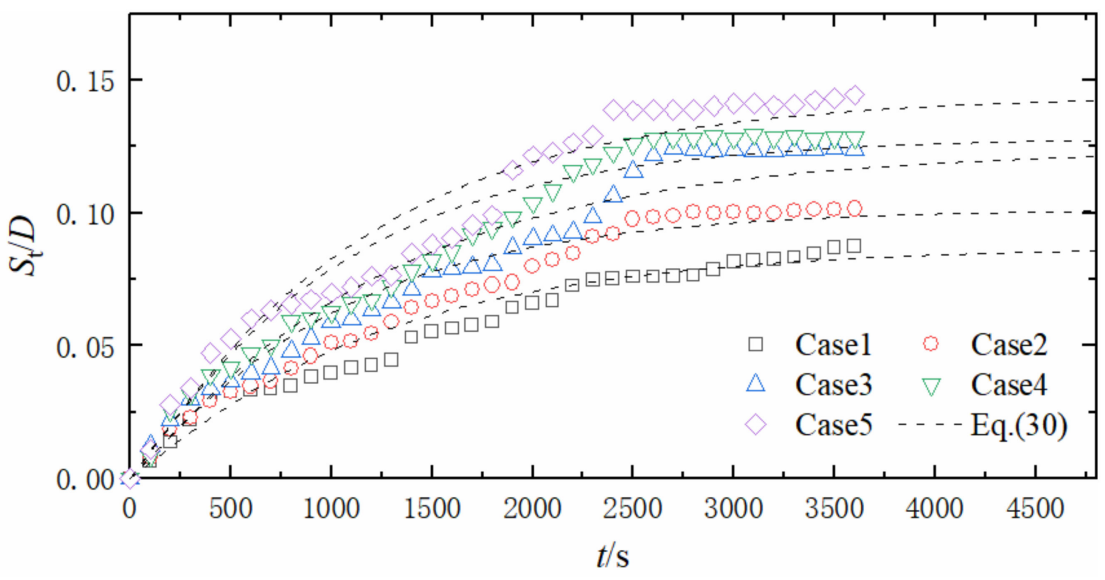

(a)

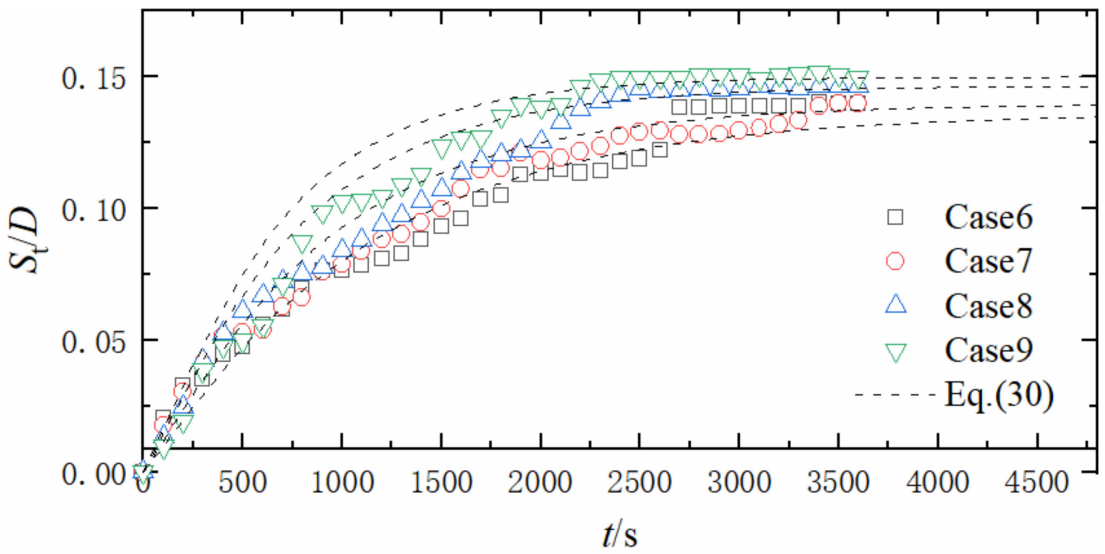

(b)

Figure 8. Time evolution of scour for case 1-9: (a) Case 1-5; (b) Case 6-9.

The computing time is $3600 \mathrm{~s}$ and the scour development curves in Figure $8 \mathrm{kept}$ fluctuating, meaning it's still not in equilibrium scour stage in these cases. According to Sumer and Fredsøe [16], the equilibrium scour depth can be acquired by fitting the data with Equation (30). From Figure 8, it can be seen that the scour evolution obtained from 
Equation (30) is consistent with the present study basically at initial stage, but the scour depth predicted by Equation (30) developed slightly faster than the simulating results and the Equation (30) overestimated the scour depth to some extent. Overall, the whole tendency of the results calculated by Equation (30) agrees well with the simulating results of the present study, which means the Equation (30) is applicable to depict the scour evolution around USAF under random waves.

\subsection{Scour Mechanism under Random Waves}

The scour morphology and scour evolution around USAF are similar under random waves in case 1 9. Taking case 7 as an example, the scour morphology is shown in Figure 9.
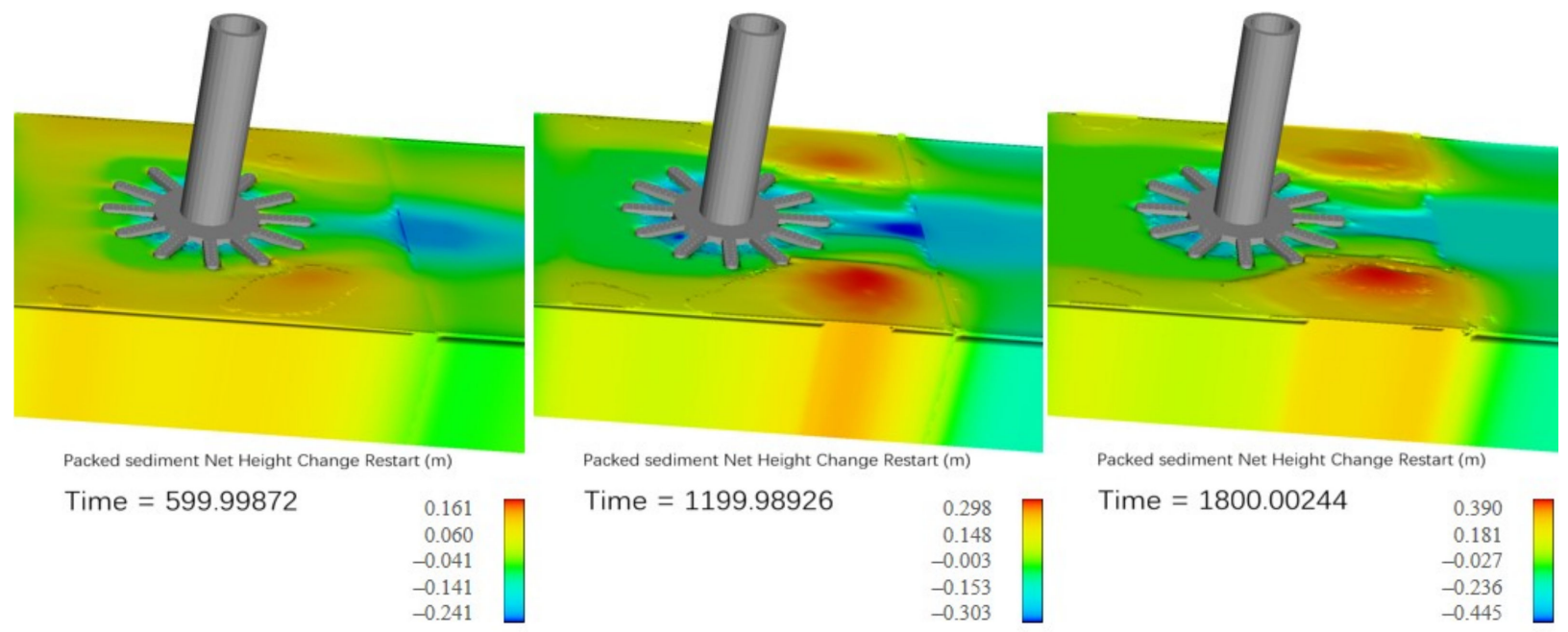

Time $=1800.00244$
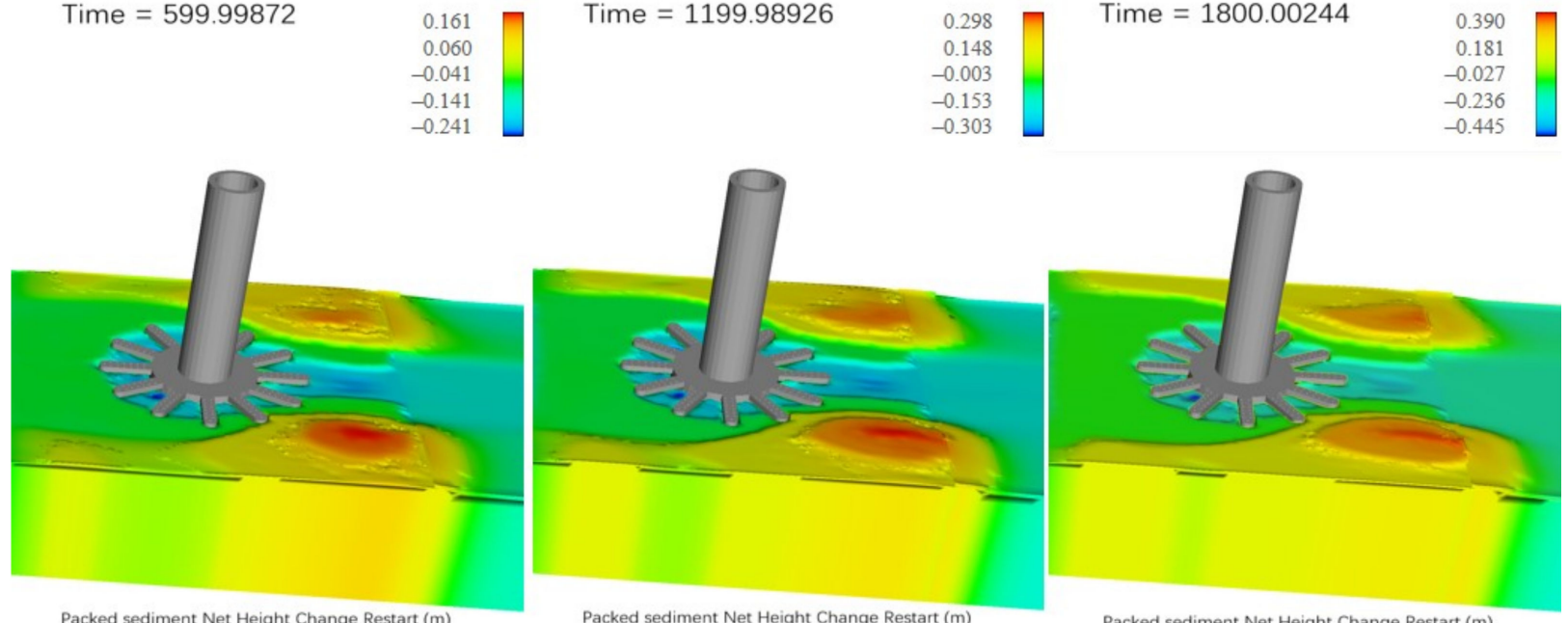

Time $=2399.99829$

Packed sediment Net Height Change Restart (m)

Time $=2999.99780$

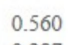

0.297

0.034

$-0.228$

$-0.491$
Packed sediment Net Height Change Restart (m)

Time $=3600.00635$

Figure 9. Scour morphology under different times for case 7.

From Figure 9, at the initial stage $(t<1200 \mathrm{~s})$, the scour occurred at upstream foundation edges between neighboring anchor branches. The maximum scour depth appeared at the lee-side of the USAF. Correspondingly, the sediments deposited at the periphery of the USAF, and the location of the maximum accretion depth was positioned at an angle of about $45^{\circ}$ symmetrically with respect to the wave propagating direction in the lee-side of the USAF. After that, when $t>2400 \mathrm{~s}$, the location of the maximum scour depth shifted to the upside of the USAF at an angle of about $45^{\circ}$ with respect to the wave propagating direction.

According to previous studies $[1,15,16,19,30,31]$, the horseshoe vortex, streamline compression and wake vortex shedding were responsible for scour around foundation. The Figure 10 displays the distribution of flow velocity in vicinity of foundation, which reflects the evolving processes of horseshoe vertex. 


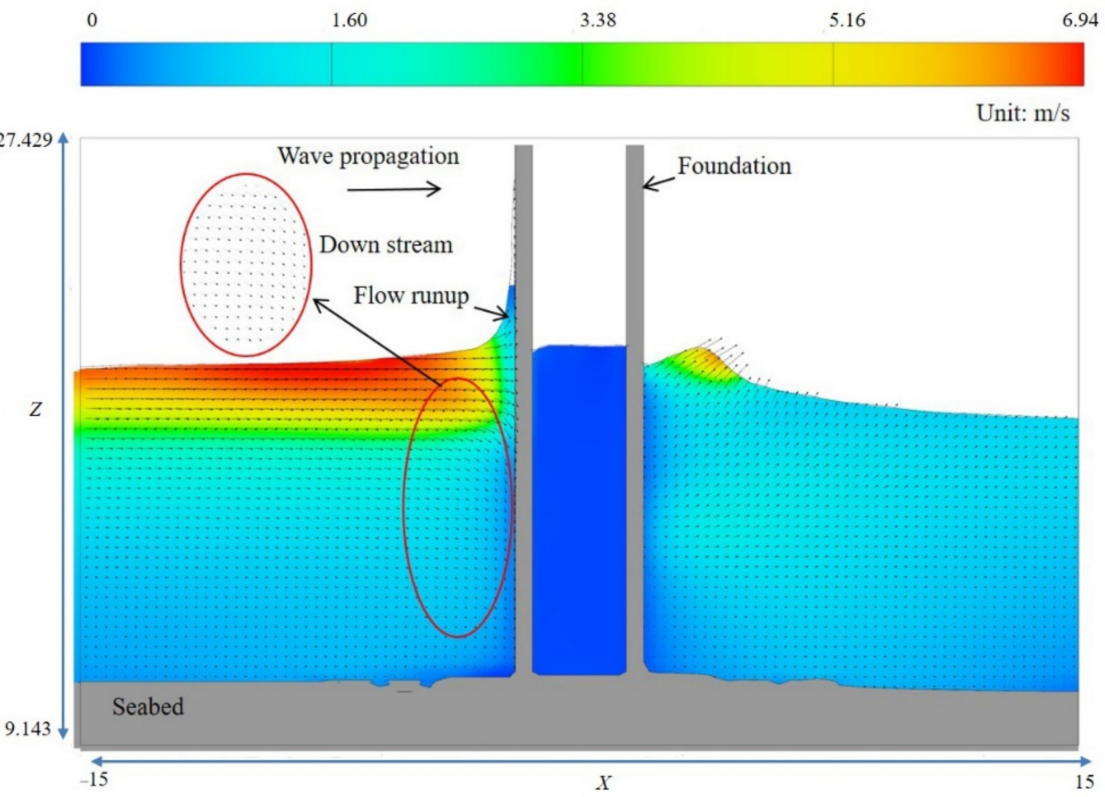

(a)
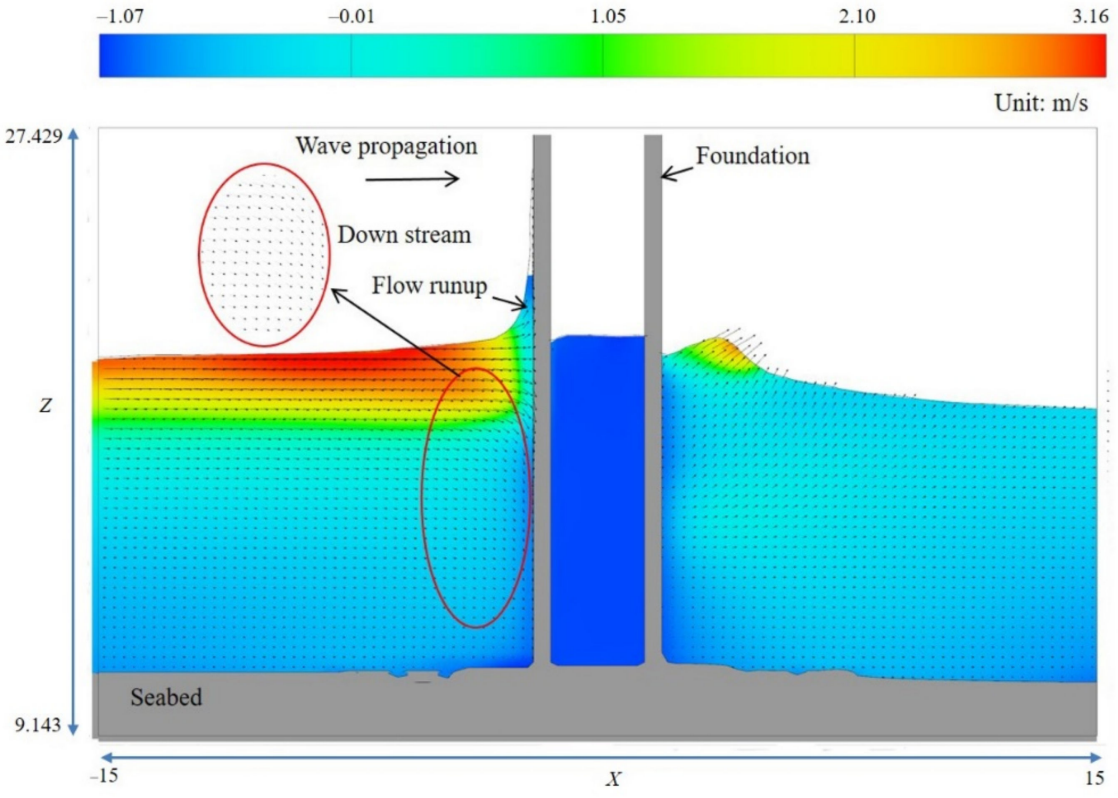

(b)

Figure 10. Cont. 


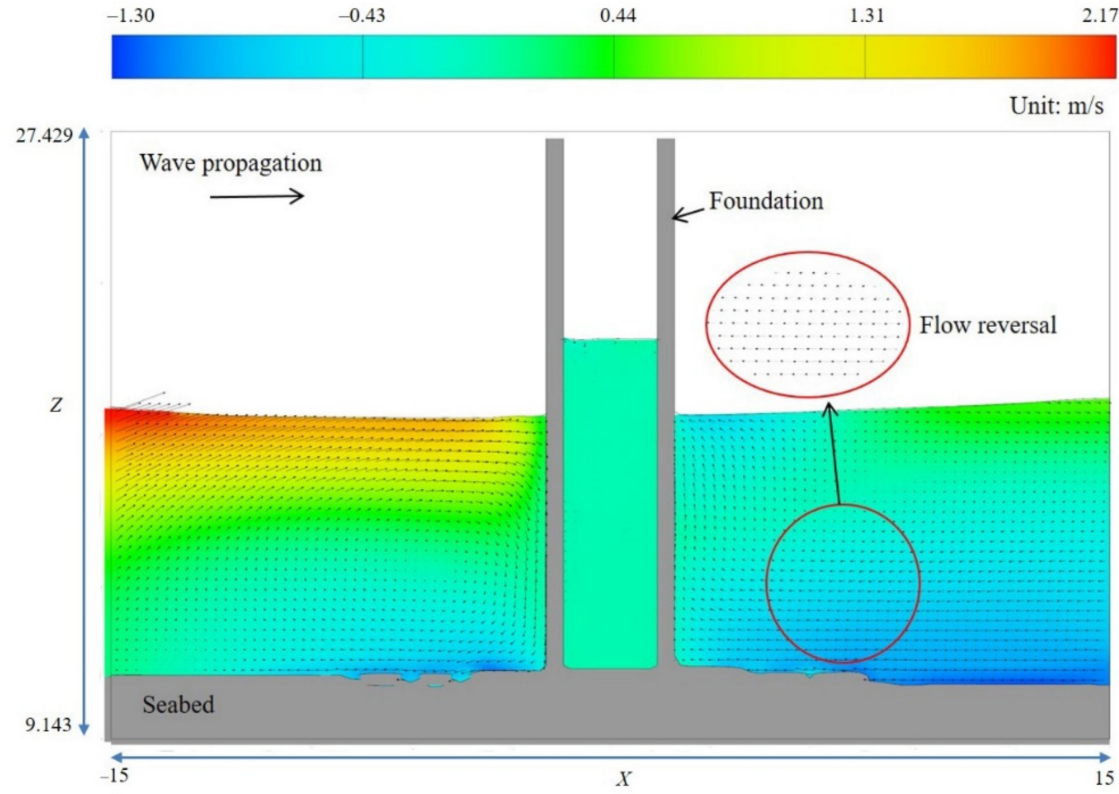

(c)

Figure 10. Velocity profile around USAF: (a) Flow runup and down stream at upstream anchor edges; (b) Horseshoe vortex at upstream anchor edges; (c) Flow reversal during wave through stage at lee side.

As shown in Figure 10, the inflow tripped to the upstream edges of the USAF and it was blocked by the upper tube of USAF. Then, the downflow formed the horizontal axis clockwise vortex and rolled on the seabed bypassing the tube, that is, the horseshoe vortex (Figure 11). The Figure 12 displays the turbulence intensity around the tube on the seabed. From Figure 12, it can be seen that the turbulence intensity was high-intensity with respect to the region of horseshoe vortex. This phenomenon occurred because of drastic water flow momentum exchanging in the horseshoe vortex. As a result, it created the prominent shear stress on the seabed, causing the local scour at the upstream edges of USAF. Besides, the horseshoe vortex moved downstream gradually along the periphery of the tube and the wake vortex shed off continually at the lee-side of the USAF, i.e., wake vortex.

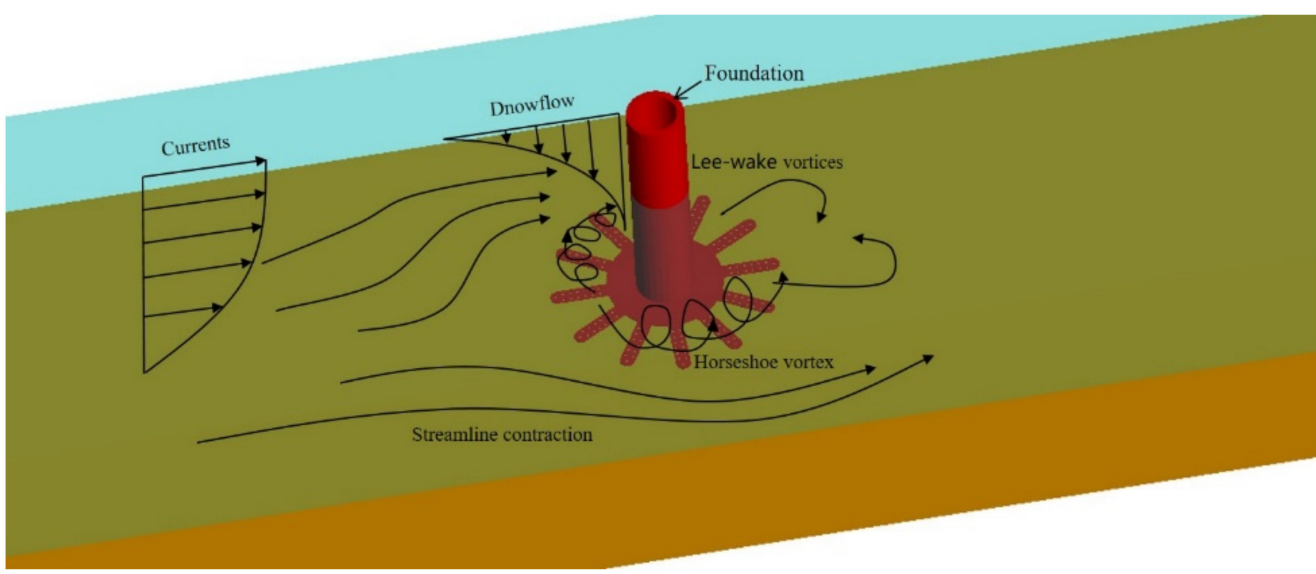

Figure 11. Sketch of scour mechanism around USAF under random waves. 


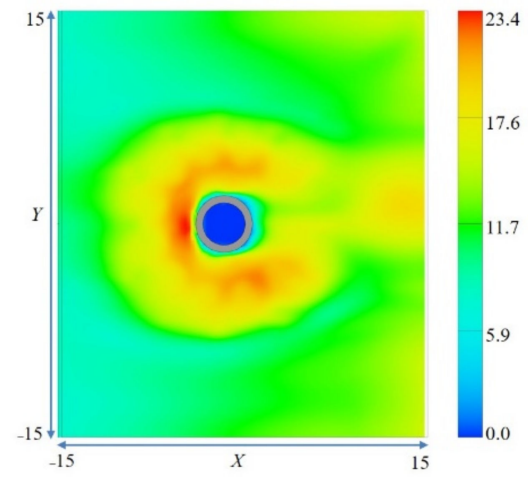

(a)

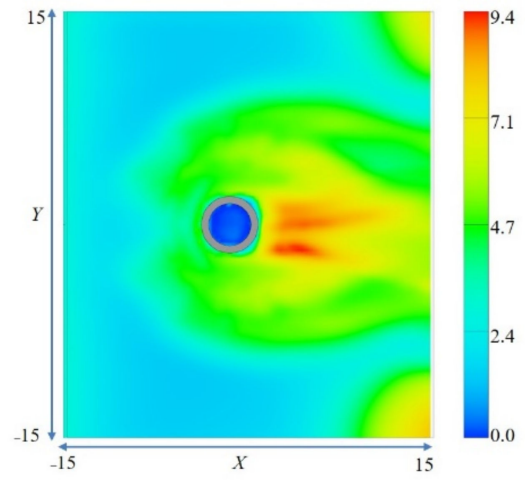

(b)

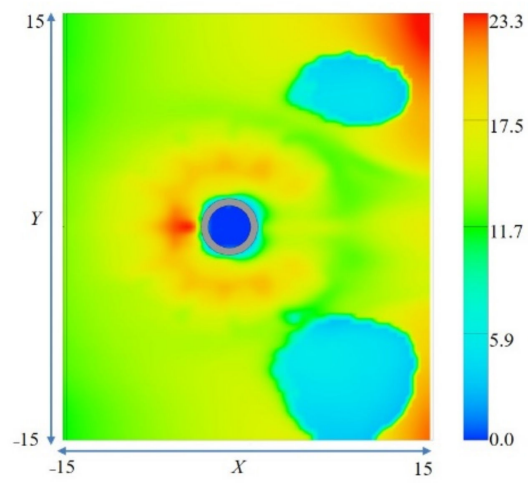

(c)

Figure 12. Turbulence intensity: (a) Turbulence intensity of horseshoe vortex; (b) Turbulence intensity of wake vortex; (c) Turbulence intensity of accretion area.

The core of wake vortex is a negative pressure center, liking a vacuum cleaner [11,42]. Hence, the soil particles were swirled into the negative pressure core and carried away by wake vortex. At the same time, the onset of scour at rear side occurred. Finally, the wake vortex became downflow at the downside of USAF. As is shown in Figure 12, the turbulence intensity was low where the downflow occurred at lee-side, which means the turbulence energy may not be able to support the survival of wake vortex, leading to accretion happening. As mentioned in previous section, the formation of horseshoe vortex was dependent with adverse pressure gradient at upside of foundation. As shown in Figure 13, the evaluated range of pressure distribution is $-15 \mathrm{~m}$ to $15 \mathrm{~m}$ in $x$ direction. The $t=450 \mathrm{~s}$ and $t=1800 \mathrm{~s}$ indicate that the wave crest and trough arrived at the upside and leeside of the foundation respectively, and the $t=350 \mathrm{~s}$ was neither the wave crest nor trough. The adverse gradient pressure reached the maximum value at $t=450 \mathrm{~s}$ corresponding to the wave crest phase. In this case, it's helpful for the wave boundary separating fully from seabed, which leads to the formation of horseshoe vortex with high turbulence intensity. Therefore, the horseshoe vortex is responsible for the local scour between neighboring anchor branches at upside of USAF. What's more, due to the combination of the horseshoe vortex and streamline compression, the maximum scour depth occurred at the upside of the USAF with an angle of about $45^{\circ}$ corresponding to the wave propagating direction. This is consistent with the findings of Pang et al. [48] and Sumer et al. [1,15] in case of regular waves. At the wave trough phase $(t=1800 \mathrm{~s})$, the pressure gradient became positive at upstream USAF edges, which hindered the separating of wave boundary from seabed. In the meantime, the flow reversal occurred (Figure 10) and the adverse gradient pressure appeared at downstream USAF edges, but the magnitude of adverse gradient pressure at lee-side was lower than the upstream gradient pressure under wave crest. In this way, the intensity of horseshoe vortex behind the USAF under wave trough was low, which explains 
the difference of scour depth at upstream and downstream, i.e., the scour asymmetry. In other words, the scour asymmetry at upside and downside of USAF was attributed to wave asymmetry for random waves, and the phenomenon became more evident for nonlinear waves [21]. Briefly speaking, the vortex system at wave crest phase was mainly related to the scour process around USAF under random waves.

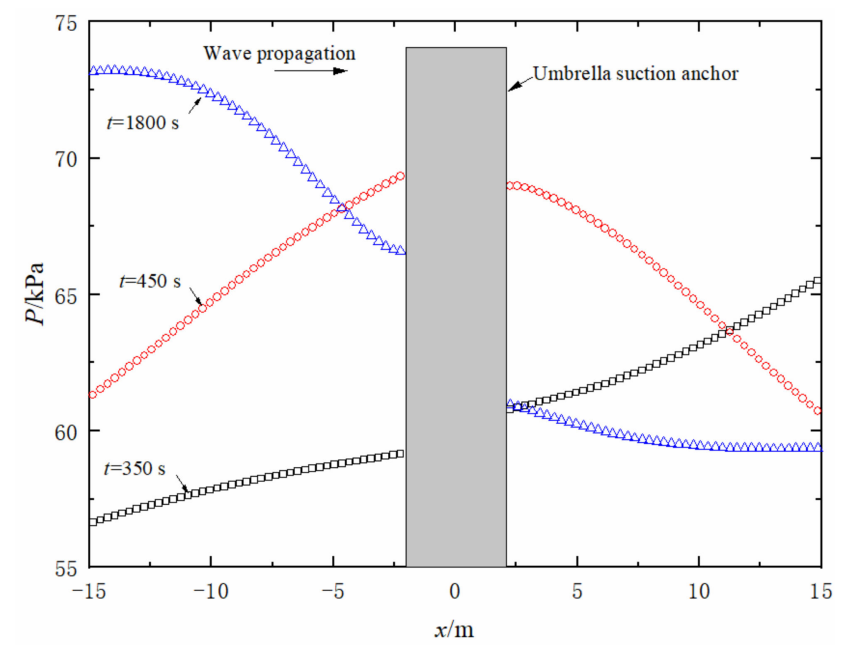

Figure 13. Pressure distribution around USAF.

\subsection{Equilibrium Scour Depth}

The $K C$ number is a key parameter for horseshoe vortex emerging and evolving under waves. According to Equation (1), when pile diameter $D$ is fixed, the $K C$ depends on the maximum near-bed velocity $U_{\mathrm{wm}}$ and wave period $T$. For random waves, the $U_{\mathrm{wm}}$ can be denoted by the root-mean-square (RMS) value of near-bed velocity amplitude $U_{\mathrm{wm}, \mathrm{rms}}$ or the significant value of near-bed velocity amplitude $U_{\mathrm{wm}, \mathrm{s}}$. The $U_{\mathrm{wm}, \mathrm{rms}}$ and $U_{\mathrm{wm}, \mathrm{s}}$ for all simulating cases of the present study are listed in Tables 3 and 4 . The $T$ can be denoted by the mean up zero-crossing wave period $T_{\mathrm{a}}$, peak wave period $T_{\mathrm{p}}$, significant wave period $T_{\mathrm{s}}$, the maximum wave period $T_{\mathrm{m}}, 1 / 10^{\prime}$ th highest wave period $T_{\mathrm{n}=1 / 10}$ and $1 / 5^{\prime}$ th highest wave period $T_{\mathrm{n}=1 / 5}$ for random waves, so the different combinations of $U_{\mathrm{wm}}$ and $T$ will acquire different $K C$. The Tables 3 and 4 list 12 types of $K C$, for example, the $K C_{\mathrm{rms}, \mathrm{s}}$ was calculated by $U_{\mathrm{wm}, \mathrm{rms}}$ and $T_{\mathrm{s}}$. Sumer and Fredsøe [16] conducted a series of wave flume experiments to investigate the scour depth around monopile under random waves, and found the equilibrium scour depth predicting equation (Equation (2)) for regular waves was applicable for random waves with $K C_{\text {rms,p. }}$. It should be noted that the Equation (2) is only suitable for $K C>6$ under regular waves or $K C_{\mathrm{rms}, \mathrm{p}}>6$ under random waves.

Table 3. $U_{\mathrm{wm}, \mathrm{rms}}$ and $K C$ for case 1 9.

\begin{tabular}{|c|c|c|c|c|c|c|c|}
\hline Case & $U_{\mathrm{wm}, \mathrm{rms}}$ & $K C_{\mathrm{rms}, \mathrm{a}}$ & $K C_{\mathrm{rms}, \mathrm{p}}$ & $K C_{\mathrm{rms}, \mathrm{s}}$ & $K C_{\mathrm{rms}, \mathrm{m}}$ & $K C_{\mathrm{rms}, \mathrm{n}}=\mathbf{1 / 1 0}$ & $K C_{\mathrm{rms}, \mathrm{n}}=1 / 5$ \\
\hline 1 & 0.882 & 1.462 & 1.938 & 1.805 & 1.781 & 1.496 & 1.372 \\
\hline 2 & 1.080 & 1.940 & 2.573 & 2.396 & 2.364 & 1.986 & 1.822 \\
\hline 3 & 1.285 & 2.511 & 3.330 & 3.101 & 3.060 & 2.571 & 2.358 \\
\hline 4 & 1.470 & 2.981 & 3.953 & 3.681 & 3.633 & 3.052 & 2.799 \\
\hline 5 & 1.655 & 3.490 & 4.629 & 4.309 & 4.253 & 3.573 & 3.277 \\
\hline 6 & 1.526 & 3.219 & 4.270 & 3.975 & 3.923 & 3.296 & 3.023 \\
\hline 7 & 1.414 & 2.982 & 3.955 & 3.682 & 3.634 & 3.053 & 2.800 \\
\hline 8 & 1.314 & 2.773 & 3.677 & 3.424 & 3.379 & 2.839 & 2.604 \\
\hline 9 & 1.229 & 2.593 & 3.439 & 3.202 & 3.160 & 2.655 & 2.435 \\
\hline
\end{tabular}


Table 4. $U_{\mathrm{wm}, \mathrm{s}}$ and $K C$ for case 1 9.

\begin{tabular}{cccccccc}
\hline Case & $\boldsymbol{U}_{\mathbf{w m}, \mathbf{s}}$ & $K C_{\mathbf{s}, \mathbf{s}}$ & $K C_{\mathbf{s , \mathbf { p }}}$ & $K C_{\mathbf{s}, \mathbf{a}}$ & $K C_{\mathbf{s}, \mathbf{m}}$ & $K C_{\mathbf{s}, \mathbf{n}=\mathbf{1} / \mathbf{1 0}}$ & $K C_{\mathbf{s , \mathbf { n }}=\mathbf{1} / \mathbf{5}}$ \\
\hline 1 & 1.390 & 2.844 & 3.055 & 2.303 & 2.807 & 2.358 & 2.163 \\
2 & 1.670 & 3.705 & 3.980 & 3.001 & 3.657 & 3.072 & 2.818 \\
3 & 1.955 & 4.719 & 5.068 & 3.822 & 4.657 & 3.913 & 3.588 \\
4 & 2.220 & 5.561 & 5.973 & 4.503 & 5.488 & 4.611 & 4.229 \\
5 & 2.489 & 6.482 & 6.963 & 5.250 & 6.398 & 5.375 & 4.929 \\
6 & 2.314 & 6.026 & 6.472 & 4.880 & 5.947 & 4.997 & 4.582 \\
7 & 2.165 & 5.639 & 6.056 & 4.567 & 5.565 & 4.676 & 4.288 \\
8 & 2.033 & 5.296 & 5.688 & 4.289 & 5.227 & 4.391 & 4.027 \\
9 & 1.919 & 4.998 & 5.368 & 4.048 & 4.933 & 4.144 & 3.801 \\
\hline
\end{tabular}

Raaijmakers and Rudolph [34] proposed the equilibrium scour depth predicting model (Equation (5)) around pile under waves, which is suitable for low KC. The format of Equation (5) is similar with the formula proposed by Breusers [54], which can predict the equilibrium scour depth around pile at different scour stages. In order to verify the applicability of Raaijmakers's model for predicting the equilibrium scour depth around USAF under random waves, a validation of the equilibrium scour depth $S_{\text {eq }}$ between the present study and Raaijmakers's equation was conducted. The position where the scour depth $S_{\text {eq }}$ was evaluated is the location of the maximum scour depth, and it was depicted in Figure 14. The Figure 15 displays the comparison of $S_{\text {eq }}$ with different $K C$ between the present study and Raaijmakers's model.

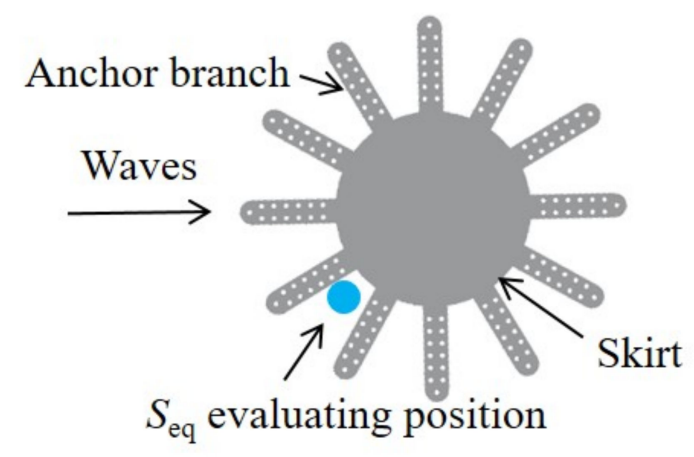

Figure 14. Sketch of the position where the $S_{\text {eq }}$ was evaluated.

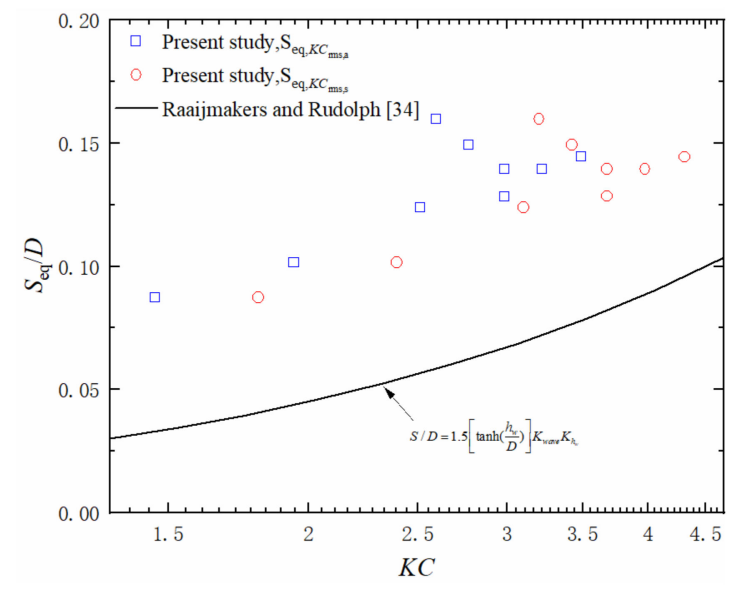

(a)

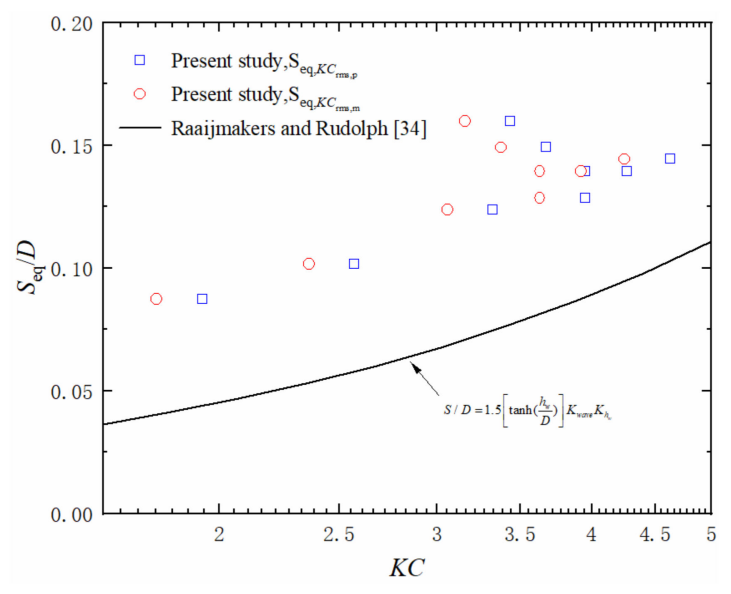

(b)

Figure 15. Cont. 


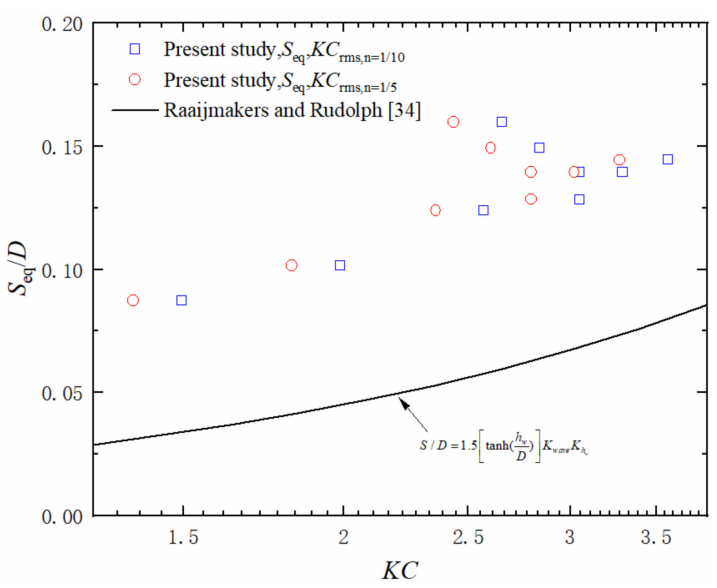

(c)

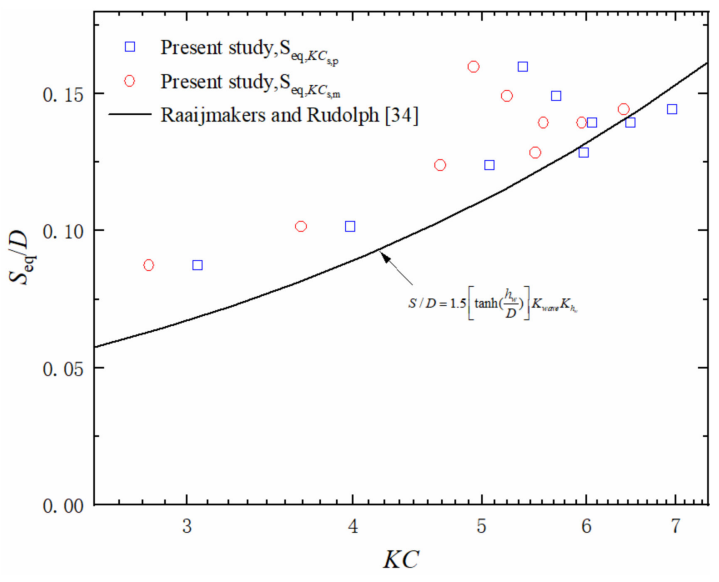

(e)

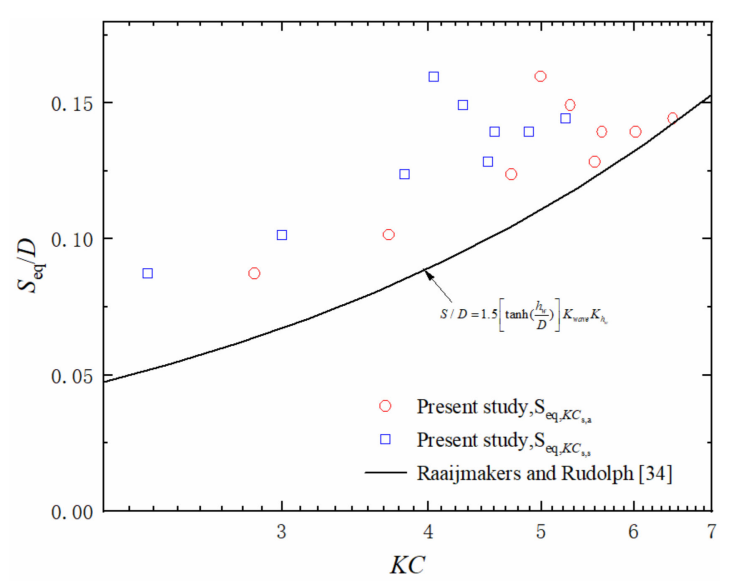

(d)

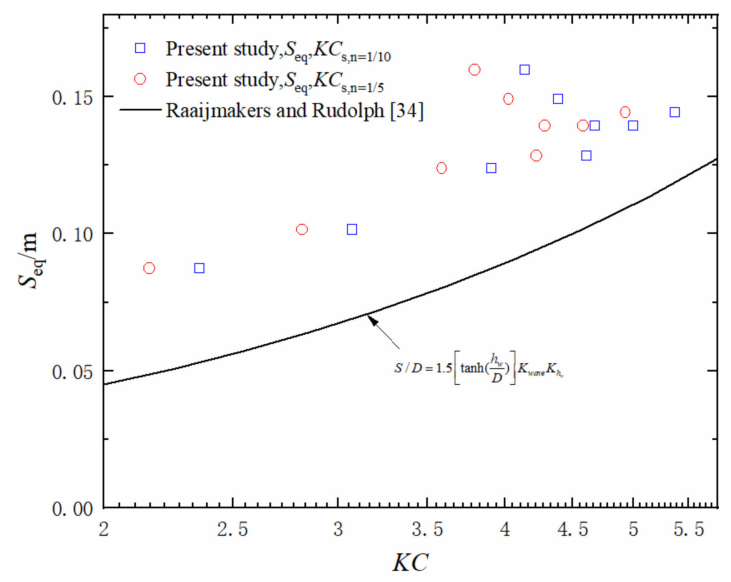

(f)

Figure 15. Comparison of the equilibrium scour depth between the present model and the model of Raaijmakers and Rudolph [34]: (a) $K C_{\mathrm{rms}, \mathrm{s}}, K C_{\mathrm{rms}, \mathrm{a}}$; (b) $K C_{\mathrm{rms}, \mathrm{p}}, K C_{\mathrm{rms}, \mathrm{m}}$; (c) $K C_{\mathrm{rms}, \mathrm{n}=1 / 10}, K C_{\mathrm{rms}, \mathrm{n}=1 / 5}$; (d) $K C_{\mathrm{s}, \mathrm{s}}, K C_{\mathrm{s}, \mathrm{a}} ;(\mathbf{e}) K C_{\mathrm{s}, \mathrm{p}}, K C_{\mathrm{s}, \mathrm{m}}$; (f) $K C_{\mathrm{s}, \mathrm{n}=1 / 10}, K C_{\mathrm{s}, \mathrm{n}=1 / 5}$.

As shown in Figure 15, there is an error in predicting $S_{\text {eq }}$ between the present study and Raaijmakers's model, and Raaijmakers's model underestimates the results generally. Although the error exists, the varying trend of $S_{\text {eq }}$ with $K C$ obtained from Raaijmakers's model is consistent with the present study basically. What's more, the error is minimum and the Raaijmakers's model is of relatively high accuracy for predicting scour around USAF under random waves by using $K C_{\mathrm{s}, \mathrm{p}}$. Based on this, a further revision was made to eliminate the error as much as possible, i.e., add the deviation value $\Delta S / D$ in the Raaijmakers's model. The revised equilibrium scour depth predicting equation based on Raaijmakers's model can be written as

$$
S_{\text {eq }}^{\prime} / D=1.95\left[\tanh \left(\frac{h}{D}\right)\right]\left(1-\exp \left(-0.012 K C_{\mathrm{s}, \mathrm{p}}\right)\right)+\Delta S / D
$$

As the Figure 16 shown, through trial-calculation, when $\Delta S / D=0.05$, the results calculated by Equation (31) show good agreement with the simulating results of the present study. The maximum error is about $18.2 \%$ and the engineering requirements have been met basically. In order to further verify the accuracy of the revised model for large $K C$ $\left(K C_{\mathrm{s}, \mathrm{p}}>4\right)$ under random waves, a validation between the revised model and the previous experimental results [21]. The experiment was conducted in a flume $(50 \mathrm{~m}$ in length, $1.0 \mathrm{~m}$ in width and $1.3 \mathrm{~m}$ in height) with a slender vertical pile $(D=0.1 \mathrm{~m})$ under random waves. The seabed is composed of $0.13 \mathrm{~m}$ deep layer of sand with $d_{50}=0.6 \mathrm{~mm}$ and the water depth 
is $0.5 \mathrm{~m}$ for all tests. The significant wave height is $0.12 \sim 0.21 \mathrm{~m}$ and the $K C_{\mathrm{s}, \mathrm{p}}$ is $5.52 \sim 11.38$. The comparison between the predicting results by Equation (31) and the experimental results of Corvaro et al. [21] is shown in Figure 17. From Figure 17, the experimental data evenly distributes around the predicted results and the prediction accuracy is favorable when $K C_{\mathrm{s}, \mathrm{p}}<8$. However, the gap between the predicting results and experimental data becomes large and the Equation (31) overestimates the equilibrium scour depth to some extent when $K C_{\mathrm{s}, \mathrm{p}}>8$.

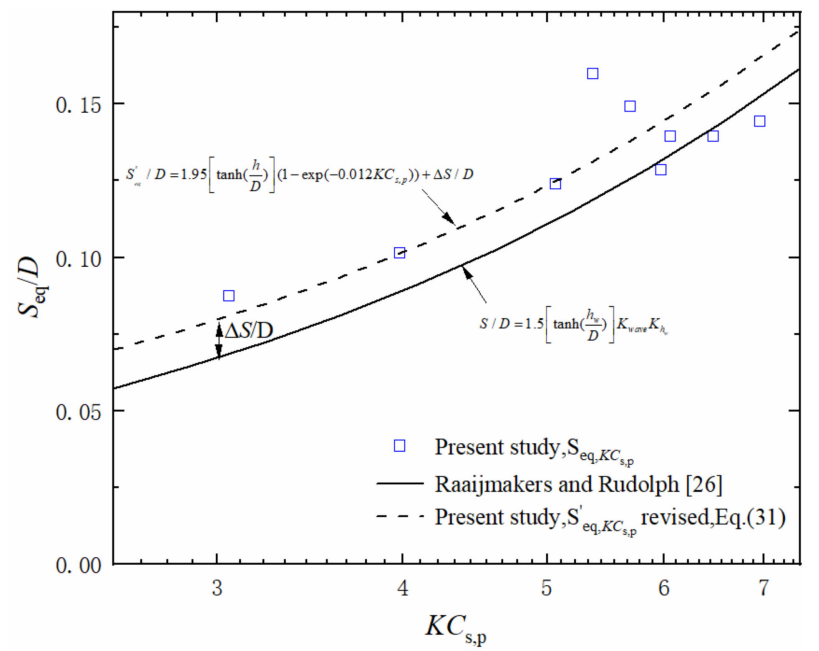

Figure 16. Comparison of $S_{\text {eq }}$ between the simulating results and the predicting values by Equation (31).

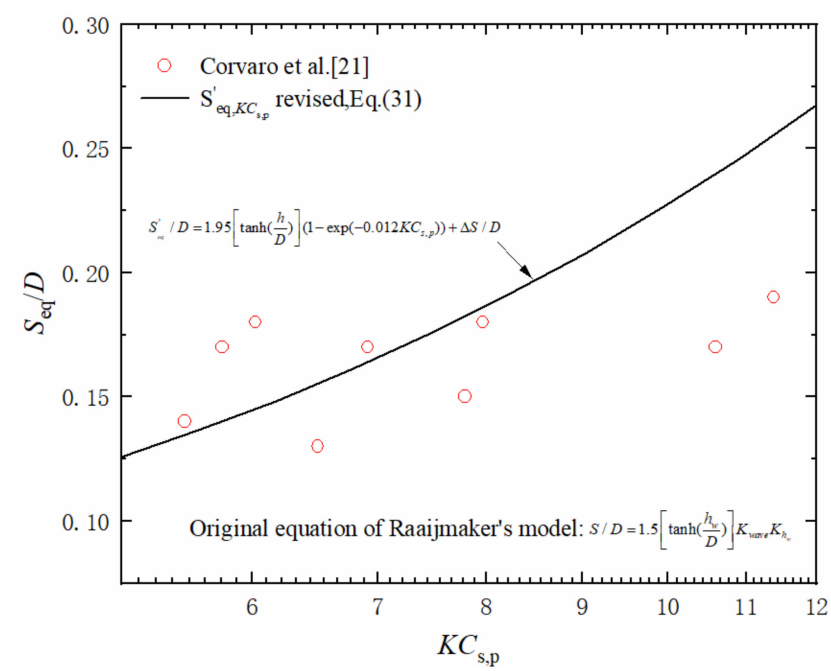

Figure 17. Comparison of $S_{\text {eq }} / D$ between the Experimental results of Corvaro et al. [21] and the predicting values by Equation (31).

In ocean environment, the waves are composed of a train of sinusoidal waves with different frequencies and amplitudes. The energy of constituent waves with very large and very small frequencies is relatively low, and the energy of waves is mainly concentrated in a certain range of moderate frequencies. Myrhaug and Rue [37] thought the $1 / n^{\prime}$ th highest wave was responsible for scour and proposed the stochastic model to predict the equilibrium scour depth around pile under random waves for full range of $K C$. Noteworthy is that the $K C$ was denoted by $K C_{\mathrm{rms}, \mathrm{a}}$ in the stochastic model. To verify the application of the stochastic model for predicting scour depth around USAF, a validation between the simulating results of present study and predicting results by the stochastic model with $n=2,3,5,10,20,500$ was carried out respectively. 
As shown in Figure 18, compared with the simulating results, the stochastic model underestimates the equilibrium scour depth around USAF generally. Although the error exists, the varying trend of $S_{\text {eq }}$ with $K C_{\mathrm{rms}, \mathrm{a}}$ obtained from the stochastic model is consistent with the present study basically. What's more, the gap between the predicting values by stochastic model and the simulating results decreases with the increase of $n$, but for large $n$, for example $n=500$, the varying trend diverges between the predicting values and simulating results, meaning it's not feasible only by increasing $n$ in stochastic model to predict the equilibrium scour depth around USAF.

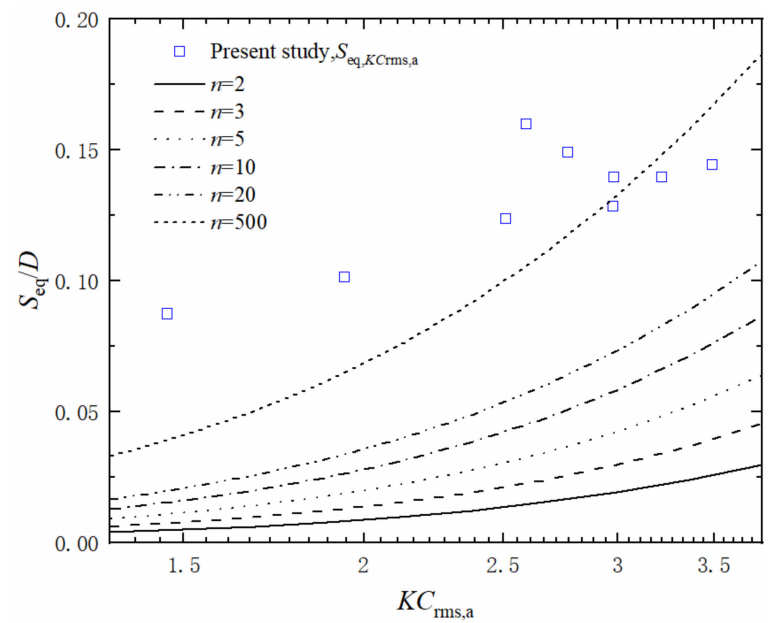

Figure 18. Comparison of $S_{\text {eq }}$ between the simulating results and the predicting values by Equation (8).

The Figure 19 lists the deviation value $\Delta S_{e q} / D^{\prime}$ between the predicting values and simulating results with different $K C_{\mathrm{rms}, \mathrm{a}}$ and $n$. Then, fitted the relationship between the $\Delta S^{\prime}$ and $n$ under different $K C_{\mathrm{rms}, \mathrm{a}}$, and the fitting curve can be written by Equation (32). The revised stochastic model (Equation (33)) can be acquired by adding $\Delta S_{e q} / D^{\prime}$ to Equation (8).

$$
\begin{gathered}
\Delta S_{\mathrm{eq}} / D=0.052 * \exp (-n / 6.566)+0.068 \\
\overline{S_{\mathrm{eq}}^{\prime}} / D=S_{\mathrm{eq}}^{\prime} / D+0.052 * \exp (-n / 6.566)+0.068
\end{gathered}
$$

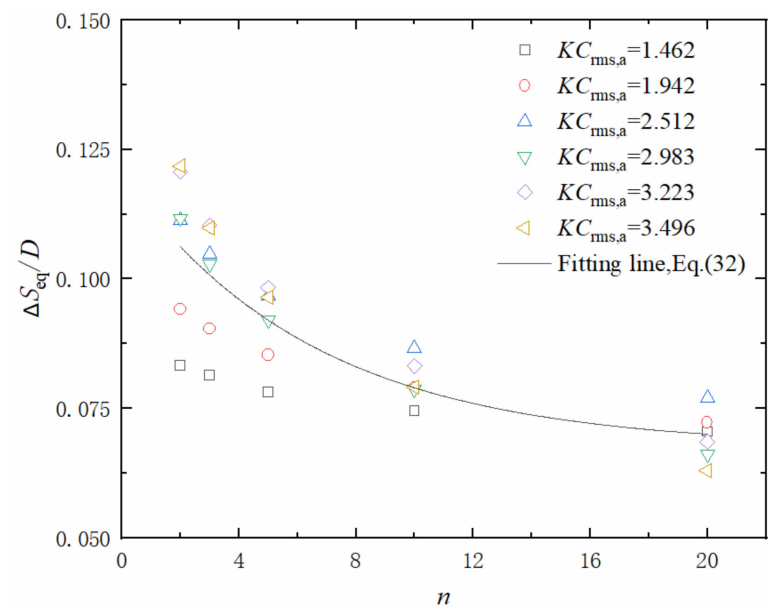

Figure 19. The fitting line between $\Delta S^{\prime}$ and $n$.

The comparison between the predicting results by Equation (33) and the simulating results of present study is shown in Figure 20. According to the Figure 20, the varying trend of $S_{\text {eq }}$ with $K C_{\mathrm{rms}, \mathrm{a}}$ obtained from the stochastic model is consistent with the present 
study basically. Compared with predicting results by the stochastic model, the results calculated by Equation (33) is favorable. Moreover, comparison with simulating results indicates that the predicting results are the most favorable for $n=10$, which is consistent with the findings of Myrhaug and Rue [37] for equilibrium scour depth predicting around slender pile in case of random waves.

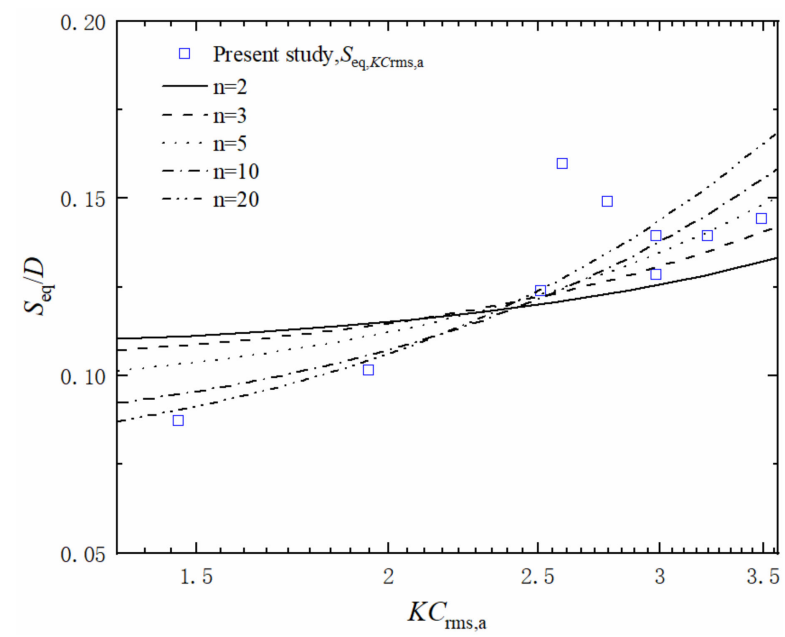

Figure 20. Comparison of $S_{\text {eq }}$ between the simulating results and the predicting values by Equation (33).

In order to further verify the accuracy of the Equation (33) for large $K C\left(K C_{\mathrm{rms}, \mathrm{a}}>4\right)$ under random waves, a validation was conducted between the Equation (33) and the previous experimental results of Sumer and Fredsøe [16] and Corvaro et al. [21]. The details of experiments conducted by Corvaro et al. [21] were described in above section. Sumer and Fredsøe [16] investigated the local scour around pile under random waves. The experiments were conducted in a wave basin with a slender vertical pile $(D=0.032$, $0.055 \mathrm{~m}$ ). The seabed is composed of $0.14 \mathrm{~m}$ deep layer of sand with $d_{50}=0.2 \mathrm{~mm}$ and the water depth was maintained at $0.5 \mathrm{~m}$. The JONSWAP wave spectrum was used and the $K C_{\mathrm{rms}, \mathrm{a}}$ was 5.29 16.95. The comparison between the predicting results by Equation (33) and the experimental results of Sumer and Fredsøe [16] and Corvaro et al. [21] are shown in Figure 21. From Figure 21, contrary to the case of low $K C_{\mathrm{rms}, \mathrm{a}}\left(K C_{\mathrm{rms}, \mathrm{a}}<4\right)$, the error between the predicting values and experimental results increases with decreasing of $n$ for $K C_{\mathrm{rms}, \mathrm{a}}>4$. Therefore, the predicting results are the most favorable for $n=2$ when $K C_{\mathrm{rms}, \mathrm{a}}>4$.

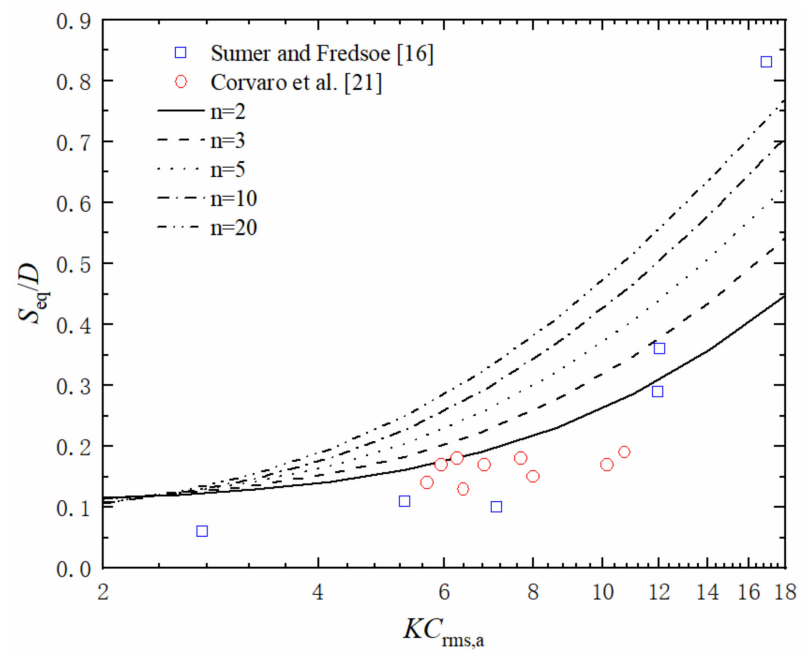

Figure 21. Comparison of $S_{\text {eq }}$ between the experimental results of Sumer and Fredsøe [16] and Corvaro et al. [21] and the predicting values by Equation (33). 
Noteworthy is that the present model was built according to prototype size, so the errors between the numerical results and experimental data of References [16,21] may be attribute to the scale effects. In laboratory experiments on scouring process, it is typically impossible to ensure a rigorous similarity of all physical parameters between the model and prototype structure, leading to the scale effects in the laboratory experiments. To avoid a cohesive behaviour, the bed material was not scaled geometrically according to model scale. As a consequence, the relatively large-scaled sediments sizes may result in the overestimation of bed load transport and underestimation of suspended load transport compared with field conditions. What's more, the disproportional scaled sediment presumably lead to the difference of bed roughness between the model and prototype, and thus large influences for wave boundary layer on the seabed and scour process. Besides, according to Corvaro et al. [21] and Schendel et al. [55], the pile Reynolds numbers and Froude numbers both affect the scour depth for the condition of non fully developed turbulent flow in laboratory experiments.

\subsection{Parametric Study}

\subsubsection{Influence of Froude Number}

As described above, the set of foundation leads to the adverse pressure gradient appearing at upstream, leading to the wave boundary layer separating from seabed, then horseshoe vortex formatting and the horseshoe vortex are mainly responsible for scour around foundation (see Figure 22). The Froude number $F_{\mathrm{r}}$ is the key parameter to influence the scale and intensity of horseshoe vortex. The $F_{\mathrm{r}}$ under waves can be calculated by the following formula [42]

$$
F_{\mathrm{r}}=\frac{U_{\mathrm{w}}}{\sqrt{g D}}
$$

where $U_{\mathrm{w}}$ is the mean water particle velocity during $1 / 4$ cycle of wave oscillation, obtained from the following formula. Noteworthy is that the root-mean-square (RMS) value of near-bed velocity amplitude $U_{\mathrm{wm}, \mathrm{rms}}$ is used for calculating $U_{\mathrm{wm}}$.

$$
U_{\mathrm{w}}=\frac{1}{T / 4} \int_{0}^{T / 4} U_{\mathrm{wm}} \sin (t / T) d t=\frac{2}{\pi} U_{\mathrm{wm}}
$$

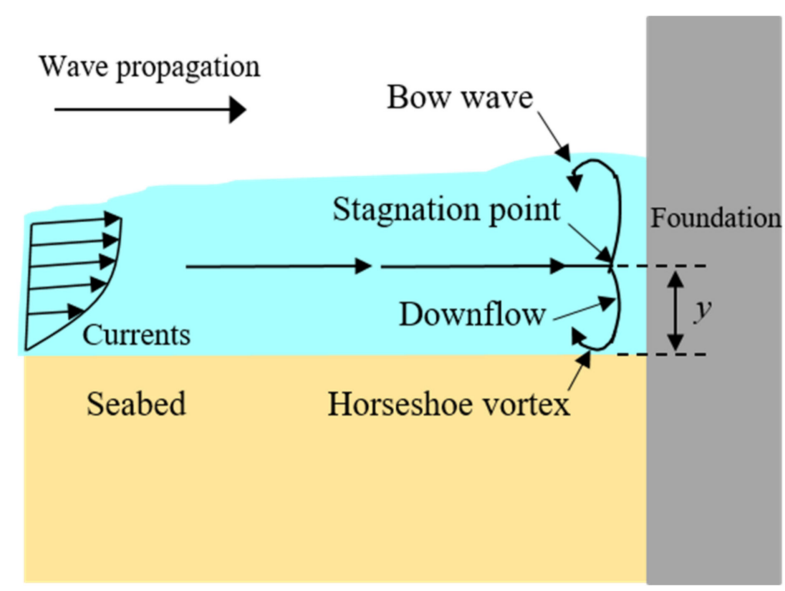

Figure 22. Sketch of flow field at upstream USAF edges.

Tavouktsoglou et al. [25] proposed the following formula between $F_{\mathrm{r}}$ and the vertical location of the stagnation $y$

$$
\frac{y}{h} \propto F_{\mathrm{r}}^{e}
$$

where $e$ is constant. 
The Figure 23 displays the relationship between $S_{\text {eq }} / D$ and $F_{\mathrm{r}}$ of the present study. In order to compare with the simulating results, the experimental data of Corvaro et al. [21] was also depicted in Figure 23. As shown in Figure 23, the equilibrium scour depth appears a logarithmic increase as $F_{\mathrm{r}}$ increases and approaches the mathematical asymptotic value, which is also consistent with the experimental results of Corvaro et al. [21]. According to Figure 24, the adverse pressure gradient pressure at upstream USAF edges increases with the increase of $F_{\mathrm{r}}$, which is benefit for the wave boundary layer separating from seabed, resulting in the high-intensity horseshoe vortex, hence, causing intensive scour around USAF. Based on the previous study of Tavouktsoglou et al. [25] for scour around pile under currents, the high $F_{\mathrm{r}}$ leads to the stagnation point is closer to the mean sea level for shallow water, causing the stronger downflow kinetic energy. As mentioned in previous section, the energy of downflow at upstream makes up the energy of the subsequent horseshoe vortex, so the stronger downflow kinetic energy results in the more intensive horseshoe vortex. Therefore, the higher $F_{\mathrm{r}}$ leads to the more intensive horseshoe vortex by influencing the position of stagnation point $y$ presumably. Qi and Gao [19] carried out a series of flume tests to investigate the scour around pile under regular waves, and proposed the fitting formula between $S_{\mathrm{eq}} / D$ and $F_{\mathrm{r}}$ as following

$$
\lg \left(S_{\mathrm{eq}} / D\right)=A \exp \left(B / F_{\mathrm{r}}\right)+C
$$

where $A, B$ and $C$ are constant.

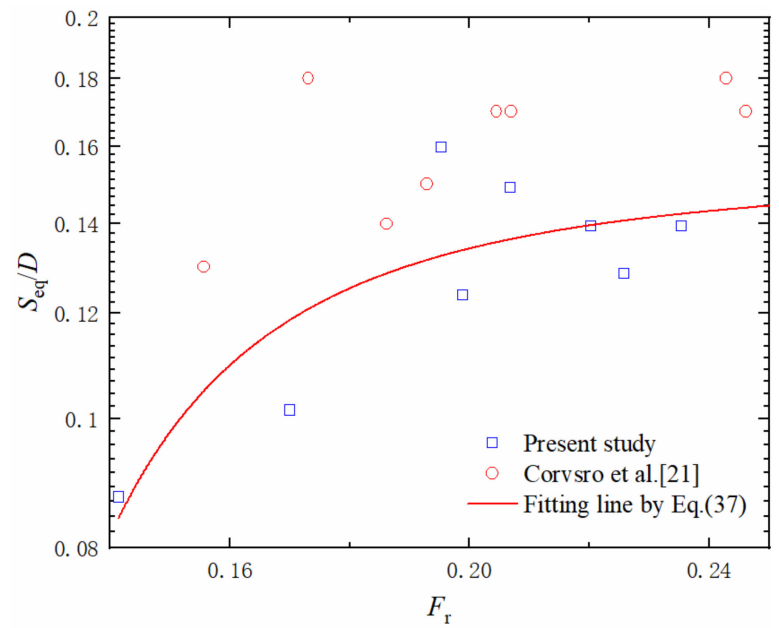

Figure 23. The fitting curve between $S_{\text {eq }} / D$ and $F_{\mathrm{r}}$.

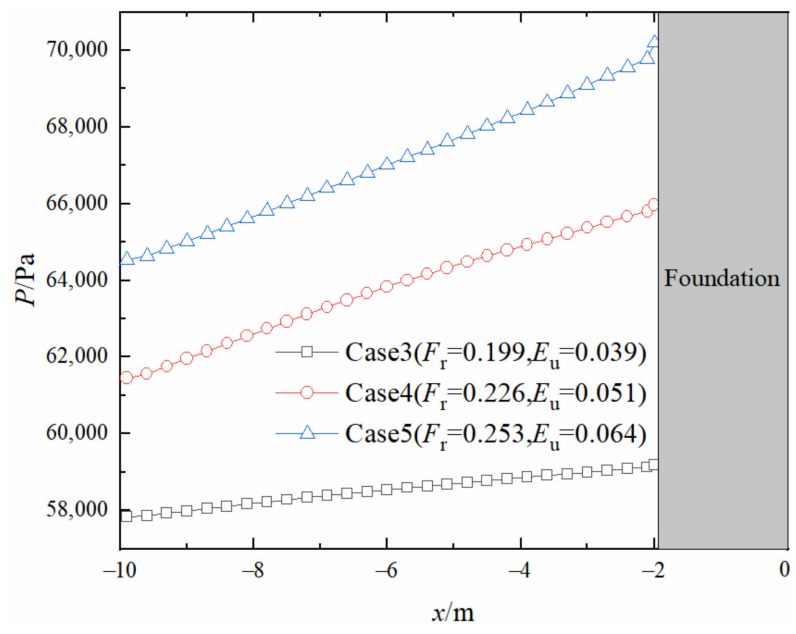

Figure 24. Sketch of adverse pressure gradient at upstream USAF edges. 
Took the Equation (37) to fit the simulating results with $A=-0.002, B=0.686$ and $C=-0.808$, and the results are shown in Figure 23. From Figure 23, the simulating results evenly distribute around the Equation (37) and the varying trend of $S_{\mathrm{eq}} / D$ and $F_{\mathrm{r}}$ in present study is consistent with Equation (37) basically, meaning the Equation (37) is applicable to express the relationship of $S_{\text {eq }} / D$ with $F_{\mathrm{r}}$ around USAF under random waves.

\subsubsection{Influence of Euler Number}

The Euler number $E_{\mathrm{u}}$ is the influencing factor for the hydrodynamic field around foundation. The $E_{\mathrm{u}}$ under waves can be calculated by the following formula. The $E_{\mathrm{u}}$ can be represented by the Equation (38) for uniform cylinders [25]. The root-mean-square (RMS) value of near-bed velocity amplitude $U_{\mathrm{m}, \mathrm{rms}}$ is used for calculating $U_{\mathrm{m}}$.

$$
E_{\mathrm{u}}=\frac{U_{\mathrm{m}}^{2}}{g D}
$$

where $U_{\mathrm{m}}$ is depth-averaged flow velocity.

The Figure 25 displays the relationship between $S_{\text {eq }} / D$ and $E_{\mathrm{u}}$ of the present study. In order to compare with the simulating results, the experimental data of Sumer and Fredsøe [16] and Corvaro et al. [21] were also plotted in Figure 25. As shown in Figure 25, similar with the varying trend of $S_{\mathrm{eq}} / D$ and $F_{\mathrm{r}}$, the equilibrium scour depth appears a logarithmic increase as $E_{\mathrm{u}}$ increases and approaches the mathematical asymptotic value, which is also consistent with the experimental results of Sumer and Fredsøe [16] and Corvaro et al. [21]. According to Figure 24, the adverse pressure gradient pressure at upstream USAF edges increases with the increasing of $E_{\mathrm{u}}$, which is benefit for the wave boundary layer separating from seabed, inducing the high-intensity horseshoe vortex, hence, causing intensive scour around USAF.

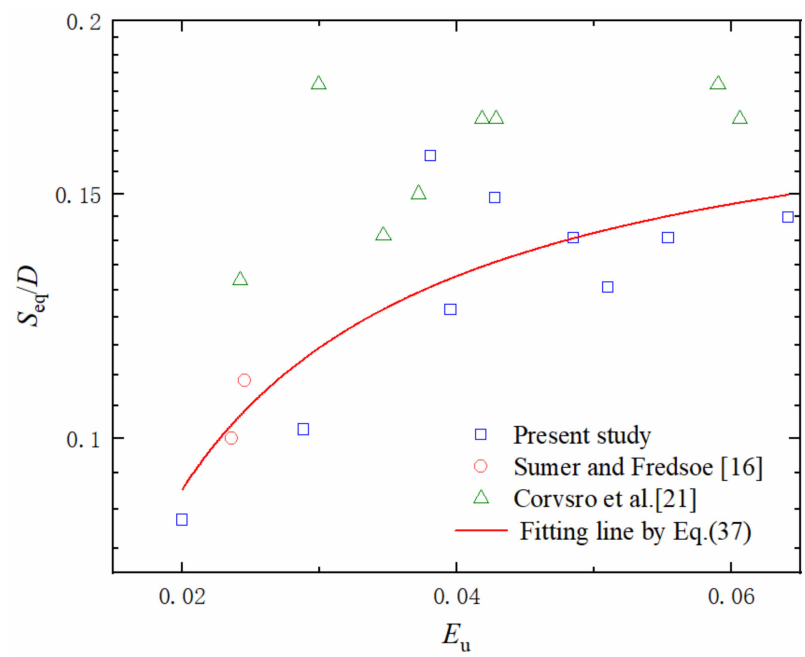

Figure 25. The fitting curve between $S_{\mathrm{eq}} / D$ and $E_{\mathrm{u}}$.

Therefore, the variation of $F_{\mathrm{r}}$ and $E_{\mathrm{u}}$ reflect the magnitude of adverse pressure gradient pressure at upstream. Given that, the Equation (37) also was used to fit the simulating results with $\mathrm{A}=8.875, \mathrm{~B}=0.078$ and $\mathrm{C}=-9.601$, and the results are shown in Figure 25 . From Figure 25, the simulating results evenly distribute around the Equation (37) and the varying trend of $S_{\mathrm{eq}} / D$ and $E_{\mathrm{u}}$ in present study is consistent with Equation (37) basically, meaning the Equation (37) is also applicable to express the relationship of $S_{\mathrm{eq}} / D$ with $E_{\mathrm{u}}$ around USAF under random waves. Additionally, according to the above description of $F_{\mathrm{r}}$, it can be inferred that the higher $F_{\mathrm{r}}$ and $E_{\mathrm{u}}$ both lead to the more intensive horseshoe vortex by influencing the position of stagnation point $y$ presumably. 


\section{Conclusions}

A series of numerical models were established to investigate the local scour around umbrella suction anchor foundation (USAF) under random waves. The numerical model was validated for hydrodynamic and morphology parameters by comparing with the experimental data of Khosronejad et al. [52], Petersen et al. [17], Sumer and Fredsøe [16] and Schendel et al. [22]. Based on the simulating results, the scour evolution and scour mechanisms around USAF under random waves were analyzed respectively. Two revised models were proposed according to the model of Raaijmakers and Rudolph [34] and the stochastic model developed by Myrhaug and Rue [37] to predict the equilibrium scour depth around USAF under random waves. Finally, a parametric study was carried out with the present model to study the effects of the Froude number $F_{\mathrm{r}}$ and Euler number $E_{\mathrm{u}}$ to the equilibrium scour depth around USAF under random waves. The main conclusions can be described as follows.

(1) The packed sediment scour model and the $R N G k-\varepsilon$ turbulence model were used to simulate the sand particles transport processes and the flow field around UASF respectively. The scour evolution obtained by the present model agrees well with the experimental results of Khosronejad et al. [52], Petersen et al. [17], Sumer and Fredsøe [16] and Schendel et al. [22], which indicates that the present model is accurate and reasonable for depicting the scour morphology around UASF under random waves.

(2) The vortex system at wave crest phase is mainly related to the scour process around USAF under random waves. The maximum scour depth appeared at the lee-side of the USAF at the initial stage $(t<1200 \mathrm{~s})$. Subsequently, when $t>2400 \mathrm{~s}$, the location of the maximum scour depth shifted to the upside of the USAF at an angle of about $45^{\circ}$ with respect to the wave propagating direction.

(3) The error is negligible and the Raaijmakers's model is of relatively high accuracy for predicting scour around USAF under random waves when $K C$ is calculated by $K C_{\mathrm{s}, \mathrm{p}}$. Given that, a further revision model (Equation (31)) was proposed according to Raaijmakers's model to predict the equilibrium scour depth around USAF under random waves and it shows good agreement with the simulating results of the present study when $K C_{\mathrm{s}, \mathrm{p}}<8$.

(4) Another further revision model (Equation (33)) was proposed according to the stochastic model established by Myrhaug and Rue [37] to predict the equilibrium scour depth around USAF under random waves, and the predicting results are the most favorable for $n=10$ when $K C_{\mathrm{rms}, \mathrm{a}}<4$. However, contrary to the case of low $K C_{\mathrm{rms}, \mathrm{a}}$, the predicting results are the most favorable for $n=2$ when $K C_{\mathrm{rms}, \mathrm{a}}>4$ by the comparison with experimental results of Sumer and Fredsøe [16] and Corvaro et al. [21].

(5) The same formula (Equation (37)) is applicable to express the relationship of $S_{\text {eq }} / D$ with $E_{\mathrm{u}}$ or $F_{\mathrm{r}}$, and it can be inferred that the higher $F_{\mathrm{r}}$ and $E_{\mathrm{u}}$ both lead to the more intensive horseshoe vortex and larger $S_{\text {eq. }}$.

Author Contributions: Conceptualization, H.L. (Hongjun Liu); Data curation, R.H. and P.Y.; Formal analysis, X.W. and H.L. (Hao Leng); Funding acquisition, X.W.; Writing-original draft, R.H. and P.Y.; Writing-review \& editing, X.W. and H.L. (Hao Leng); The final manuscript has been approved by all the authors. All authors have read and agreed to the published version of the manuscript.

Funding: This research was funded by the Fundamental Research Funds for the Central Universities (grant number 202061027) and the National Natural Science Foundation of China (grant number 41572247).

Institutional Review Board Statement: Not applicable.

Informed Consent Statement: Not applicable.

Data Availability Statement: The data presented in this study are available on request from the corresponding author.

Conflicts of Interest: The authors declare no conflict of interest. 


\section{References}

1. Sumer, B.M.; Fredsøe, J.; Christiansen, N. Scour Around Vertical Pile in Waves. J. Waterw. Port. Coast. Ocean Eng. 1992, $118,15-31$. [CrossRef]

2. Rudolph, D.; Bos, K. Scour around a monopile under combined wave-current conditions and low KC-numbers. In Proceedings of the 6th International Conference on Scour and Erosion, Amsterdam, The Netherlands, 1-3 November 2006; pp. 582-588.

3. Nielsen, A.W.; Liu, X.; Sumer, B.M.; Fredsøe, J. Flow and bed shear stresses in scour protections around a pile in a current. Coast. Eng. 2013, 72, 20-38. [CrossRef]

4. Ahmad, N.; Bihs, H.; Myrhaug, D.; Kamath, A.; Arntsen, Ø.A. Three-dimensional numerical modelling of wave-induced scour around piles in a side-by-side arrangement. Coast. Eng. 2018, 138, 132-151. [CrossRef]

5. Li, H.; Ong, M.C.; Leira, B.J.; Myrhaug, D. Effects of Soil Profile Variation and Scour on Structural Response of an Offshore Monopile Wind Turbine. J. Offshore Mech. Arct. Eng. 2018, 140, 042001. [CrossRef]

6. Li, H.; Liu, H.; Liu, S. Dynamic analysis of umbrella suction anchor foundation embedded in seabed for offshore wind turbines. Géoméch. Energy Environ. 2017, 10, 12-20. [CrossRef]

7. Fazeres-Ferradosa, T.; Rosa-Santos, P.; Taveira-Pinto, F.; Vanem, E.; Carvalho, H.; Correia, J.A.F.D.O. Editorial: Advanced research on offshore structures and foundation design: Part 1. Proc. Inst. Civ. Eng. Marit. Eng. 2019, 172, 118-123. [CrossRef]

8. Chavez, C.E.A.; Stratigaki, V.; Wu, M.; Troch, P.; Schendel, A.; Welzel, M.; Villanueva, R.; Schlurmann, T.; De Vos, L.; Kisacik, D.; et al. Large-Scale Experiments to Improve Monopile Scour Protection Design Adapted to Climate Change-The PROTEUS Project. Energies 2019, 12, 1709. [CrossRef]

9. Wu, M.; De Vos, L.; Chavez, C.E.A.; Stratigaki, V.; Fazeres-Ferradosa, T.; Rosa-Santos, P.; Taveira-Pinto, F.; Troch, P. Large Scale Experimental Study of the Scour Protection Damage Around a Monopile Foundation Under Combined Wave and Current Conditions. J. Mar. Sci. Eng. 2020, 8, 417. [CrossRef]

10. Sørensen, S.P.H.; Ibsen, L.B. Assessment of foundation design for offshore monopiles unprotected against scour. Ocean Eng. 2013, 63, 17-25. [CrossRef]

11. Prendergast, L.; Gavin, K.; Doherty, P. An investigation into the effect of scour on the natural frequency of an offshore wind turbine. Ocean Eng. 2015, 101, 1-11. [CrossRef]

12. Fazeres-Ferradosa, T.; Chambel, J.; Taveira-Pinto, F.; Rosa-Santos, P.; Taveira-Pinto, F.; Giannini, G.; Haerens, P. Scour Protections for Offshore Foundations of Marine Energy Harvesting Technologies: A Review. J. Mar. Sci. Eng. 2021, 9, 297. [CrossRef]

13. Yang, Q.; Yu, P.; Liu, Y.; Liu, H.; Zhang, P.; Wang, Q. Scour characteristics of an offshore umbrella suction anchor foundation under the combined actions of waves and currents. Ocean Eng. 2020, 202, 106701. [CrossRef]

14. Yu, P.; Hu, R.; Yang, J.; Liu, H. Numerical investigation of local scour around USAF with different hydraulic conditions under currents and waves. Ocean Eng. 2020, 213, 107696. [CrossRef]

15. Sumer, B.M.; Christiansen, N.; Fredsøe, J. The horseshoe vortex and vortex shedding around a vertical wall-mounted cylinder exposed to waves. J. Fluid Mech. 1997, 332, 41-70. [CrossRef]

16. Sumer, B.M.; Fredsøe, J. Scour around Pile in Combined Waves and Current. J. Hydraul. Eng. 2001, 127, 403-411. [CrossRef]

17. Petersen, T.U.; Sumer, B.M.; Fredsøe, J. Time scale of scour around a pile in combined waves and current. In Proceedings of the 6th International Conference on Scour and Erosion, Paris, France, 27-31 August 2012.

18. Petersen, T.U.; Sumer, B.M.; Fredsøe, J.; Raaijmakers, T.C.; Schouten, J.-J. Edge scour at scour protections around piles in the marine environment-Laboratory and field investigation. Coast. Eng. 2015, 106, 42-72. [CrossRef]

19. Qi, W.; Gao, F. Equilibrium scour depth at offshore monopile foundation in combined waves and current. Sci. China Ser. E Technol. Sci. 2014, 57, 1030-1039. [CrossRef]

20. Larsen, B.E.; Fuhrman, D.R.; Baykal, C.; Sumer, B.M. Tsunami-induced scour around monopile foundations. Coast. Eng. 2017, 129, 36-49. [CrossRef]

21. Corvaro, S.; Marini, F.; Mancinelli, A.; Lorenzoni, C.; Brocchini, M. Hydro- and Morpho-dynamics Induced by a Vertical Slender Pile under Regular and Random Waves. J. Waterw. Port. Coast. Ocean Eng. 2018, 144, 04018018. [CrossRef]

22. Schendel, A.; Welzel, M.; Schlurmann, T.; Hsu, T.-W. Scour around a monopile induced by directionally spread irregular waves in combination with oblique currents. Coast. Eng. 2020, 161, 103751. [CrossRef]

23. Fazeres-Ferradosa, T.; Taveira-Pinto, F.; Romão, X.; Reis, M.; das Neves, L. Reliability assessment of offshore dynamic scour protections using copulas. Wind. Eng. 2018, 43, 506-538. [CrossRef]

24. Fazeres-Ferradosa, T.; Welzel, M.; Schendel, A.; Baelus, L.; Santos, P.R.; Pinto, F.T. Extended characterization of damage in rubble mound scour protections. Coast. Eng. 2020, 158, 103671. [CrossRef]

25. Tavouktsoglou, N.S.; Harris, J.M.; Simons, R.R.; Whitehouse, R.J.S. Equilibrium Scour-Depth Prediction around Cylindrical Structures. J. Waterw. Port. Coast. Ocean Eng. 2017, 143, 04017017. [CrossRef]

26. Ettema, R.; Melville, B.; Barkdoll, B. Scale Effect in Pier-Scour Experiments. J. Hydraul. Eng. 1998, 124, 639-642. [CrossRef]

27. Umeda, S. Scour Regime and Scour Depth around a Pile in Waves. J. Coast. Res. Spec. Issue 2011, 64, 845-849.

28. Umeda, S. Scour process around monopiles during various phases of sea storms. J. Coast. Res. 2013, 165, 1599-1604. [CrossRef]

29. Baykal, C.; Sumer, B.; Fuhrman, D.R.; Jacobsen, N.; Fredsøe, J. Numerical simulation of scour and backfilling processes around a circular pile in waves. Coast. Eng. 2017, 122, 87-107. [CrossRef]

30. Miles, J.; Martin, T.; Goddard, L. Current and wave effects around windfarm monopile foundations. Coast. Eng. 2017, 121, 167-178. [CrossRef] 
31. Miozzi, M.; Corvaro, S.; Pereira, F.A.; Brocchini, M. Wave-induced morphodynamics and sediment transport around a slender vertical cylinder. Adv. Water Resour. 2019, 129, 263-280. [CrossRef]

32. Yu, T.; Zhang, Y.; Zhang, S.; Shi, Z.; Chen, X.; Xu, Y.; Tang, Y. Experimental study on scour around a composite bucket foundation due to waves and current. Ocean Eng. 2019, 189, 106302. [CrossRef]

33. Carreiras, J.; Larroudé, P.; Seabra-Santos, F.; Mory, M. Wave Scour Around Piles. In Proceedings of the Coastal Engineering 2000 American Society of Civil Engineers (ASCE), Sydney, Australia, 16-21 July 2000; pp. 1860-1870.

34. Raaijmakers, T.; Rudolph, D. Time-dependent scour development under combined current and waves conditions-Laboratory experiments with online monitoring technique. In Proceedings of the 4th International Conference on Scour and Erosion, Tokyo, Japan, 5-7 November 2008; pp. 152-161.

35. Khalfin, I.S. Modeling and calculation of bed score around large-diameter vertical cylinder under wave action. Water Resour. 2007, 34, 357. [CrossRef]

36. Zanke, U.C.; Hsu, T.-W.; Roland, A.; Link, O.; Diab, R. Equilibrium scour depths around piles in noncohesive sediments under currents and waves. Coast. Eng. 2011, 58, 986-991. [CrossRef]

37. Myrhaug, D.; Rue, H. Scour below pipelines and around vertical piles in random waves. Coast. Eng. 2003, 48, 227-242. [CrossRef]

38. Myrhaug, D.; Ong, M.C.; Føien, H.; Gjengedal, C.; Leira, B.J. Scour below pipelines and around vertical piles due to second-order random waves plus a current. Ocean Eng. 2009, 36, 605-616. [CrossRef]

39. Myrhaug, D.; Ong, M.C. Random wave-induced onshore scour characteristics around submerged breakwaters using a stochastic method. Ocean Eng. 2010, 37, 1233-1238. [CrossRef]

40. Ong, M.C.; Myrhaug, D.; Hesten, P. Scour around vertical piles due to long-crested and short-crested nonlinear random waves plus a current. Coast. Eng. 2013, 73, 106-114. [CrossRef]

41. Yakhot, V.; Orszag, S.A. Renormalization group analysis of turbulence. I. Basic theory. J. Sci. Comput. 1986, 1, 3-51. [CrossRef]

42. Yakhot, V.; Smith, L.M. The renormalization group, the e-expansion and derivation of turbulence models. J. Sci. Comput. 1992, 7, 35-61. [CrossRef]

43. Mastbergen, D.R.; Berg, J.V.D. Breaching in fine sands and the generation of sustained turbidity currents in submarine canyons. Sedimentology 2003, 50, 625-637. [CrossRef]

44. Soulsby, R. Dynamics of Marine Sands; Thomas Telford Ltd.: London, UK, 1998. [CrossRef]

45. Van Rijn, L.C. Sediment Transport, Part I: Bed Load Transport. J. Hydraul. Eng. 1984, 110, 1431-1456. [CrossRef]

46. Zhang, Q.; Zhou, X.-L.; Wang, J.-H. Numerical investigation of local scour around three adjacent piles with different arrangements under current. Ocean Eng. 2017, 142, 625-638. [CrossRef]

47. Yu, Y.X.; Liu, S.X. Random Wave and Its Applications to Engineering, 4th ed.; Dalian University of Technology Press: Dalian, China, 2011.

48. Pang, A.; Skote, M.; Lim, S.; Gullman-Strand, J.; Morgan, N. A numerical approach for determining equilibrium scour depth around a mono-pile due to steady currents. Appl. Ocean Res. 2016, 57, 114-124. [CrossRef]

49. Higuera, P.; Lara, J.L.; Losada, I.J. Three-dimensional interaction of waves and porous coastal structures using Open-FOAM ${ }^{\circledR}$ Part I: Formulation and validation. Coast. Eng. 2014, 83, 243-258. [CrossRef]

50. Corvaro, S.; Crivellini, A.; Marini, F.; Cimarelli, A.; Capitanelli, L.; Mancinelli, A. Experimental and Numerical Analysis of the Hydrodynamics around a Vertical Cylinder in Waves. J. Mar. Sci. Eng. 2019, 7, 453. [CrossRef]

51. Flow3D User Manual, version 11.0.3; Flow Science, Inc.: Santa Fe, NM, USA, 2013.

52. Khosronejad, A.; Kang, S.; Sotiropoulos, F. Experimental and computational investigation of local scour around bridge piers. Adv. Water Resour. 2012, 37, 73-85. [CrossRef]

53. Stahlmann, A. Experimental and Numerical Modeling of Scour at Foundation Structures for Offshore Wind Turbines. Ph.D. Thesis, Franzius-Institute for Hydraulic, Estuarine and Coastal Engineering, Leibniz Universität Hannover, Hannover, Germany, 2013.

54. Breusers, H.N.C.; Nicollet, G.; Shen, H. Local Scour Around Cylindrical Piers. J. Hydraul. Res. 1977, 15, 211-252. [CrossRef]

55. Schendel, A.; Hildebrandt, A.; Goseberg, N.; Schlurmann, T. Processes and evolution of scour around a monopile induced by tidal currents. Coast. Eng. 2018, 139, 65-84. [CrossRef] 